https://helda.helsinki.fi

\title{
Ants reign over a distinct microbiome in forest soil
}

\section{Lindström, Stafva}

2019-12

Lindström , S , Timonen , S , Sundström , L \& Johansson , H 2019 , ' Ants reign over a distinct microbiome in forest soil ' , Soil Biology \& Biochemistry , vol. 139 , 107529 . https://doi.org/10.1016/j.soilbio.2

http://hdl.handle.net/10138/335620

https://doi.org/10.1016/j.soilbio.2019.107529

cc_by_nc_nd

acceptedVersion

Downloaded from Helda, University of Helsinki institutional repository.

This is an electronic reprint of the original article.

This reprint may differ from the original in pagination and typographic detail.

Please cite the original version. 


\title{
Ants reign over a distinct microbiome in forest soil
}

\author{
Stafva Lindström ${ }^{1,2 *}$, Sari Timonen ${ }^{3}$, Liselotte Sundström ${ }^{1,2}$, Helena Johansson ${ }^{1,2}$ \\ ${ }^{1}$ Organismal and Evolutionary Biology Research Program, Faculty of Biological and Environmental \\ sciences, University of Helsinki, P O Box 56, 00014 Helsinki, Finland \\ ${ }^{2}$ Tvärminne Zoological Station, J. A. Palménin tie 260, 10900 Hanko, Finland \\ ${ }^{3}$ Department Microbiology, University of Helsinki, P O Box 56, 00014 Helsinki, Finland
}

\begin{abstract}
Biotic and abiotic characteristics shape the microbial communities in the soil environment. Manipulation of soil, performed by ants when constructing their nests, radically changes the soil characteristics and creates a unique environment, which differs in its composition, frequency and abundance of microbial taxa, from those in the reference soils. We sampled nests of the moundbuilding ant Formica exsecta, and the surrounding reference soils over a three-month period, and generated NGS (Illumina MiSeq), and T-RFLP data of the bacterial and fungal communities. We used ordination techniques and network analysis to disclose the community structure, and we assessed the variation in diversity, evenness and enrichment of taxa between the two environments. We also used indicator analysis to identify the potential core microbiome of the nests. Our results show that the bacterial and fungal communities, in the rigorously curated nest environment, are significantly different from those in the reference soils, in terms of community structure and enrichment of characteristic indicator taxa. We demonstrate that the nests represent a niche, where microbial species can adapt and diverge from the communities in the surrounding soils. Our findings contribute to our understanding of the composition and function of microbiomes in fragmented habitats.
\end{abstract}

\section{Key words}

Microbial community structure, wood ant nests, indicator taxa, fragmented habitat, boreal forest

\section{Introduction}

In a forest landscape, the distribution of microbes varies both in spatial and temporal dimensions (Lladó et al., 2018; Männistö et al., 2018; Vořřšková and Baldrian, 2013). The spatial distribution encompasses clustering across areas of some centimetres to several kilometres, as well as vertical clustering, beneath the litter layer, following the stratification of the soil (Kadowaki et al., 2014). The spatial variation of the upper soil layers are tightly interlinked with the temporal variation, caused by seasonal changes in temperature, precipitation, photosynthesis and litter production, (Žifčáková et al., 
2017). Furthermore, the distribution of microbes in soil is also affected by manipulation of soil, whether it is compaction carried out by humans (Hartmann et al., 2014) or bioturbation performed by animals (Nkem et al., 2000).

Many organisms actively modify the dynamics of their habitats to better suit their needs, thereby increasing the heterogeneity of their surroundings, changing the abiotic variables and their impact on the biotic communities. Organisms that actively modify the dynamics of their habitats are often referred to as ecosystem engineers (Hastings et al., 2007; Jones et al., 1994; Jouquet et al., 2006; Lavelle et al., 2006). By their engineering actions, these organisms also affect the availability of resources for other species (Hastings et al., 2007). For example, beavers profoundly change the prevailing hydrological characteristics by building their dams, creating large wetlands that provide suitable habitats for other species, such as otters or riparian plants (Rosell et al., 2005). On dry land many invertebrates, such as ants, engineer the ecosystem by redistributing and concentrating soil and litter while building nests for themselves, simultaneously creating suitable niches for other species (Boots et al., 2012; Dauber et al., 2001; Dignac et al., 2017; Frouz and Jilková, 2008; Jílková and Frouz, 2014; Jones et al., 1994).

Ants are ubiquitous and diverse, they occupy nearly every ecological niche on earth, and have an important impact on the soil ecosystem function (King, 2016). Many ant species have an intimate interaction with soil, and have evolved mechanisms to manipulate both the soil and the organisms in it (Vander Meer, 2012). Some ant species demonstrate their soil engineering skills by excavating their dwellings beneath the soil surface, whereas some build conspicuous mounds above ground. This manipulation of mineral and organic material carried out by ants creates a distinct soil chemistry, which shapes the communities of fellow invertebrates, plants and microbes (Dauber et al., 2001; Jouquet et al., 2006), through the level of $\mathrm{pH}$, humidity and available nutrients in the habitat in question (Dostál et al., 2005). In addition, the species-specific feeding strategies and breeding habits of the host are expected to regulate the microbial communities in the nests (Boots et al., 2012; Dauber et al., 2001). For example, many species of the mound-building wood ants derive considerable amounts of honeydew from tree aphids and transport it into the nest for food. The sugar metabolism and the available surplus of sugar intensifies respiration and increases decomposition. The subsequent release of basic cations affects the microbial community through changes in the pH (Jílková et al., 2012). The release and concentration of carbon (Jílková and Frouz, 2014), nitrogen and phosphorus (Kilpeläinen et al., 2007; Lenoir et al., 2001) in the nests also differs from that in the surrounding soils.

Furthermore, some wood ants, especially those living in the sub-arctic regions, such as the Eurasian Formica s. str. (Czechowski et al., 2002), actively regulate the temperature inside their nests. For many ant species living in a climate where summers are short, a thermoregulated nest is essential for prolonging the period of breeding and foraging (Jurgensen et al., 2008). In early spring, the Formica workers generate heat by utilizing their lipid reserves, maintaining the nest temperature close to +30 ${ }^{\circ} \mathrm{C}$, regardless of much lower ambient temperatures (Jílková et al., 2015; Rosengren et al., 1987). The nest mounds are mainly built in dry, sunlit spots, providing insolation and heat during the summer (Katzerke et al., 2010; Littlewood and Young, 2008). The high and steady nest temperature is further maintained by the decomposing process (Laakso and Setälä, 1998), keeping the nest drier than the outside environment (Domisch et al., 2008; Jílková and Frouz, 2014). The temperature (Hawkes et 
al., 2011; Lladó et al., 2018), acidity (Frouz and Jilková, 2008; Jílková et al., 2015) and humidity (Barnard et al., 2013; Castro et al., 2010) are considered to be major drivers of distribution, composition and abundance of microbial communities in soil environments. In the nests of Formica wood ants, these drivers would be expected to diverge from those in the surrounding soils, due to the abiotic and biotic characteristics of the nest mound, and the specific activities of the ants. So far, most of the studies on the microbial communities in ants nests have been carried out on species typical of warmer temperate, or tropical climate, such as Solenopsis fire ants (Baird et al., 2007; Ishak et al., 2011; Woolfolk et al., 2016), or Atta leaf-cutting ants (Duarte et al., 2014; Rodrigues et al., 2005), leaving the microbes associated with the boreal ant species practically unexplored.

We hypothesized that the nest of a Formica ant represents a unique environment, containing bacterial and fungal taxa, which are specifically adapted to the nest environment. We expected this to manifest itself as a difference in the composition, frequency, and abundance of these taxa, compared to the ones in the background soil. We also hypothesized that there would be key characteristic taxa within the microbiome of the nest environment that remain constant during the ant-active season. To investigate the validity of our hypotheses, we analysed the microbial communities in the nest soil of the wood ant Formica exsecta (Nylander 1846), as well as in a reference environment, during a three month period. We generated NGS (Illumina MiSeq) and T-RFLP data, and compared the microbial communities of the two environments (nest vs. reference soils) by ordination techniques, and network analysis. Furthermore, we analysed the levels of functional patterns, and compared diversity and evenness between nests and reference soils, and assessed the enrichment of taxa between the two environments at the level of phylum and genus. Finally, we used indicator analysis to determine the identity, and potential function of taxa that were consistently and significantly characteristic to either environment, and analysed their occurrence patterns in the nests and the reference soils.

\section{Methods}

\subsection{Study objects and sampling}

The ant Formica exsecta inhabits meadows and dry woodlands, and prefers sunny openings (Czechowski et al., 2002), where they construct their above-ground nest mounds. The nests are built of materials gathered from the surroundings, mainly pine and spruce needles, small twigs, and pieces of moss, lichen etc. (Jurgensen et al., 2008). The average lifespan of a nest has been estimated at 6.5 years (Haag-Liautard et al., 2009), but a nest can stay active up to 30 years (Pamilo, 1991). At our study site (Fig. S1), on the islands of Furuskär and Joskär, close to the Tvärminne zoological station (59 $84^{\prime} 196$ 'N, $\left.23^{\circ} 20^{\prime} 182^{\prime \prime} \mathrm{E}\right)$ on the SW coast of Finland, the F. exsecta populations have been monitored since 1994 (Sundström et al., 1996; Vitikainen et al., 2011). These two islands represent a typical diverse biotope for this area, with habitats that consist of pine and juniper thickets, rich in ericoid shrubs, alternating with smooth granite cliffs, dry meadows and lusher grove like patches (Lindström et al., 2018). All the sampled nest mounds were void of live plants, regardless of the surrounding habitat.

We sampled the nest material of 20 active nests (nest environments) together with a sample from the soil surrounding each nest (reference soils), in May, June and August 2015, in total 120 nest and reference soil samples. Nest samples comprised $\sim 0.21$ of material, sampled from the nest dome at a depth of $10-15 \mathrm{~cm}$, and nest locations were recorded with a Garmin GPS map60 (Garmin, Olathe, 
KS, U.S). The reference soil samples were taken from a spot resembling the environmental conditions of the nest (similar moisture and exposure to light or shade, and without perennial plant cover), $2.5-$ $3 \mathrm{~m}$ away from the focal nest. The samples of the reference soils $(\sim 0.21 /$ sample) were taken from the surface litter to a depth of $5-15 \mathrm{~cm}$, depending on the thickness of the litter layer. As the nest mounds remain inhabited for several years, and therefore contain litter from a long period of time, we included material from the entire litter layer into the reference samples to gain comparable reference material. The sampling depths were approximately according to those in previous studies on Formica ants (in relation to soil fauna (Lenoir et al., 2003a), clear fells (Sorvari et al., 2016), detrital food webs (Laakso and Setälä, 1998) or $\mathrm{CO}_{2}$ emission (Jílková and Frouz, 2014). The reference soil sample spots were marked with flags during the first sampling in May, for easy retrieval upon consecutive samplings. All samples were collected by hand, using sterile gloves, and stored in ziplock bags at $-80^{\circ} \mathrm{C}$, until further processing.

DNA was extracted from a $\sim 0.25 \mathrm{~g}$ randomly taken subsample of nest material or reference soil, using the PowerSoil ${ }^{\circledR}$ DNA Isolation Kit (MoBio Laboratories Inc., Carlsbad, CA, U.S) as per the manufacturer's instructions, except that TissueLyser II (Qiagen GmbH, Hilden, Germany) was used for $3 \mathrm{~min}$ at $20000 \mathrm{rpm}$ during the phase of cell lysis (Lindström et al., 2018). A subset of three randomly chosen samples from Furuskär, and three from Joskär, were submitted for sequencing by Illumina MiSeq. To get a comprehensive overview of the community dynamics of all sampled nests and reference soils, all 120 samples were subjected to T-RFLP analysis, and the results of the two analyses were used to inform each other, as in Lindström et al. (2018).

\subsection{Laboratory procedures and bioinformatics}

The subset of six nest samples and corresponding reference soil samples, from May, June and August (=36 samples) were submitted for sequencing by Illumina MiSeq. Library preparation, sequencing, and bioinformatics analyses were conducted as in Lindström et al., (2018). Briefly, the bacterial 16S region was amplified using the primers 27F (AGAGTTTGATC(A/C)TGGCTCAG, Chung et al., 2004; Weisburg et al., 1991), and pD’ (GTATTACCGCGGCTGCTG, Edwards et al., 1989). The fungal ITS2 region was amplified with the primers fITS7 (GTGA(A/G)TCATCGAATCTTTG, Ihrmark et al., 2012), and ITS4 (TCCTCCGCTTATTGATATGC, White et al., 1990). Illumina MiSeq sequencing of the libraries in pair-end mode was carried out by the DNA Sequencing and Genomics Laboratory, Institute of Biotechnology, University of Helsinki (Helsinki, Finland). Read filtering and OTU clustering (at 97\% identity) was performed using UPARSE v. 8.1 (Edgar, 2013). The SILVAv123 (Quast et al., 2013), and UNITE v7 (Kõljalg et al., 2013) databases were used as references for alignment of the bacterial and fungal sequences, respectively. Singletons, doubletons, and sequences not identified to the level of kingdom were removed prior to further analysis. The cyanobacteria/chloroplasts were not removed from the data, as they were expected to reveal details of the origin of the nest building material. The number of sequences (reads) was used as a proxy for the abundance of taxa. Furthermore, the $\mathrm{pH}$ was measured in water $\left(\mathrm{pH}_{\mathrm{w}}\right)$ and in $\mathrm{CaCl}_{2}\left(\mathrm{pH}_{\mathrm{Ca}}\right)$, from the samples in this subset. For each sample, an amount of approximately $2 \mathrm{ml}$ of nest or reference soil material (comprising $0.5-1.0 \mathrm{~g}$ ) was shaken in four $\mathrm{ml}$ of MQ-water for three minutes and left to settle for one minute, prior to measuring the $\mathrm{pHw}$-value. After the first measurement, $30 \mu \mathrm{l}$ of $\mathrm{CaCl}_{2}$ was added, the shaking was repeated and the pHCa-value was measured. 
PCR and purification of soil DNA for T-RFLP analysis was performed as in Lindström et al. (2018), but with modifications to the processing of fungal samples. Instead of targeting only the fungal ITS2 area, the whole ITS area (both ITS1 and ITS2) was targeted with the TAMRA-tagged primers ITS1F (CTTGGTCATTTAGAGGAAGTAA, Gardes and Bruns, 1993), and ITS4 (TCCTCCGCTTATTGATATGC, White et al., 1990). For bacteria, the FAM-tagged forward primer 27F (AGAGTTTGATC(A/C)TGGCTCAG, Chung et al., 2004; Weisburg et al., 1991), and the reverse primer 1387R (GGGCGG(A/T)GTGTACAAGGC, Wade et al., 1998) were used. The digestion of the bacterial and fungal sequences was carried out by the enzymes HaeIII and MspI, as in Lindström et al., (2018). The labelled bacterial and fungal terminal restriction fragments (T-RFs) were separated on an ABI-3730 (Applied Biosystems, Life Technologies, Carlsbad, CA, U.S) with the internal size standard GeneScan 500 ROX (Life Technologies, Bleiswijk, NL), and peaks were scored with GeneMapper v.5 (Applied Biosystems, Life Technologies). Peak data of T-RFs within the range of 70 to $400 \mathrm{bp}$, and above a threshold of 100 fluorescence units were extracted from GeneMapper, and imported into T-rex (http://trex.biohpc.org) for noise filtering (to remove peaks not considered to comprise unique T-RFs), alignment and binning (Culman et al., 2009). The T-RF data was normalized with the package vegan in R, prior to statistical analysis (Oksanen et al., 2011), and the number of peaks were counted. A pilot analysis of the T-RFs showed similar results for the data generated by the enzymes HaeIII and MspI. Therefore, only data generated by MspI were used in the main analyses, for both bacteria and fungi.

\subsection{Statistical analysis}

From the Illumina MiSeq OTUs (hereafter referred to as OTUs or OTU data), the number of reads, the total number of OTUs, and the number of OTUs, which were unique to either environment (detected only among the nest samples or reference soil samples), were counted. Prior to analysis, the OTU data was rarefied to the lowest number of reads in samples using the function rrarefy in the package vegan in $\mathrm{R}$ (Oksanen et al., 2011). The rarefied abundance is hereafter referred to as "total abundance" of bacteria or fungi. The average number of OTUs, the Shannon diversity indices, and Pielou's evenness estimates per sample were calculated with the package vegan (function diversity) in R. Differences between the environments in the average number of OTUs, diversity, evenness and $\mathrm{pH}$ were tested using a mixed-model ANOVA, with environment as a fixed factor, locID as a repeated random effect, and with a correction to account for multiple comparisons, implemented in the software (JMP v.13, SAS Institute Inc., Cary, NC, U.S).

To assess differences in the bacterial and fungal community compositions in the nest samples compared to the reference soil samples, Bray-Curtis inter-sample dissimilarity matrices were generated of the OTU and T-RF data, and plotted into a Principal Co-ordinates Analysis (PCoA, Legendre and Anderson, 1999). The Bray-Curtis matrices were also subjected to a permutational ANOVA (PERMANOVA) with 999 permutations to test the effect of environment (nest vs. reference soil), together with the effect of month, island and the physical location (locID) of each nest and reference soil pair, on the similarity of the bacterial and fungal communities in the samples. The PERMANOVA was performed using the locID of each nest and corresponding reference soil as strata, in order to constrain the permutations and account for the repeated measurement. The BrayCurtis, PCoA and the PERMANOVA were carried out in $\mathrm{R}$ with the functions vegdist, capscale and adonis2 in package vegan (Oksanen et al., 2011). PCoA and PERMANOVA were carried out on both 
the Illumina MiSeq (OTU) data, and, to confirm the trends from the OTU data, on the more extensive T-RFLP data.

To explore the correlation patterns of the microbial communities across nests and reference soils, networks were constructed with the CoNet app (Faust et al., 2015) in Cytoscape v 3.5.1 (Shannon et al., 2003) on the OTU data. OTUs with fewer than 20 sequencing reads were discarded, and the data were normalized by column. Pearson correlations were generated, and only correlations (edges) significant at or below 0.001 (Fisher's Z score) after Bonferroni corrections for multiple tests, were retained. Networks were visualized with the prefuse force directed layout in Cytoscape, and OTUs with indicator values above 0.5 were used to colour the networks (detailed description of the indicator analysis below). Four descriptors for undirected networks were extracted for the whole networks, or the largest subnetworks, using the network analysis function in Cytoscape: clustering coefficient (number of actual edges in network divided by number of possible edges, averaged over the total network), network centralization (topology measure, from centralized to decentralized), network density (normalized measure for average connectivity of a node in the network) and network heterogeneity (tendency of hub nodes). Networks were initially generated separately for each month, and, subsequently, further split by environment for each month and kingdom. The level of functional organisation ( $F o$, sensu Marzorati et al, 2008) of the bacterial and fungal OTUs was determined by estimating the Pareto-Lorenz curves, where the cumulative normalized number of OTUs was plotted against their respective cumulative normalized abundance (Marzorati et al., 2008). This was performed in JMP v.13 (SAS Institute Inc).

The number of bacterial and fungal reads at the level of phylum and genus were counted, and the effect of environment on the total abundance was analysed using a mixed-model ANOVA in JMP v.13 (SAS Institute Inc, USA), with locID as a repeated random effect, and a correction implemented into the software to account for multiple comparisons. In order to identify the OTUs that represent bacterial and fungal taxa, which are indicators for either environment, we computed Indicator values (Dufrêne and Legendre, 1997), separately for each sampled month, for both the bacterial and fungal OTUs. An indicator taxon is evenly abundant, and predominantly found in a specific environment or habitat type. The analysis calculates Indicator values between zero (no association with the specific environment), and one (strongly associated with the specific environment), and tests the significance of the association. The analysis was performed in $\mathrm{R}$ using the indval function in the indicspecies package (Cáceres and Legendre, 2009), with $p \leq 0.05$ as the cut-off. Based on the analysis, we further determined a core set of indicator taxa for each environment. This was done for bacteria by identifying the OTUs that gained indicator status in all three sampled months. Owing to the low number of fungal indicators, we relaxed the conditions to two months for fungi. The taxa represented by these OTUs were then considered as core indicators for their respective environments. In order to determine level of correspondence, we compared the indicators and the genera, which were significantly more abundant in the respective environment.

\subsection{Accession numbers}

The unprocessed sequences are available at NCBI Sequence Read Archive, Bioproject number PRJNA399258.

\section{Results}


The mean $\mathrm{pH}$ values for the nest material were $\mathrm{pHw}=4.89 \pm 0.67$, and $\mathrm{pHCa}=4.06 \pm 0.74$, and the corresponding values for the reference soils were $4.93 \pm 0.72$ and $3.94 \pm 0.78$, respectively. The difference between the two environments was not significant ( $\mathrm{pHw}: D F=1, F=0.09$ and $P=0.760$, pHCa $D F=1, F=2.31$ and $P=0.139$ ). Given the absence of significant differences, we did not include the $\mathrm{pH}$ as factors in the models.

\subsection{Bacteria}

The Illumina MiSeq sequencing produced in total 2404324 reads, 52\% of which originated from the nest samples (Table S1). The reads clustered into 5579 OTUs, 4550 of which were present in the nest samples and 5054 in the reference soil. There were 512 OTUs unique to the nest environment and 1015 OTUs unique to the reference soils. The average number of bacterial OTUs per nest was 1163.2 \pm 327.9 , significantly lower than that of reference soils $(1434.4 \pm 332.8)$ (Table 1). Diversity was significantly lower in the nests $(5.35 \pm 0.37)$ than in the reference soils $(5.60 \pm 0.45)$, whereas the evenness of OTUs did not differ between two environments. The T-RFLP, and the restriction by enzyme MspI generated 75 bacterial T-RFs from the nest samples, and 59 T-RFs from the reference soils.

Table 1. The difference in the mean number of the bacterial and fungal OTUs, the mean value of the diversity index (Shannon-Wiener) and the mean estimate of evenness (Pielou's) between the nest and the reference soil environment. Bold face values are significant at $\mathrm{P}<0.05$.

\begin{tabular}{lccccccccccc}
\hline & \multicolumn{3}{l}{ BACTERIA } & \multicolumn{1}{c}{ FUNGI } & \multicolumn{1}{c}{ Mean } & $S D$ & $d f$ & $F$ & $p$ \\
& Mean & $S D$ & $d f$ & $F$ & $p$ & Mean & \\
\hline Nbr of OTUs & & & & & & & & & & \\
Nest & 1163.22 & 327.99 & 1.00 & 18.20 & $\mathbf{0 . 0 0 1}$ & 279.00 & 57.66 & 1.00 & 1.15 & 0.293 \\
Ref. soils & 1434.44 & 332.80 & & & & 300.22 & 67.93 & & & \\
& & & & & & & & & & \\
Shannon & & & & & & & & & & \\
Nest & 5.35 & 0.37 & 1.00 & 6.81 & $\mathbf{0 . 0 1 4}$ & 3.55 & 0.72 & 1.00 & 3.89 & 0.058 \\
Ref. soils & 5.60 & 0.45 & & & & 3.97 & 0.47 & & & \\
& & & & & & & & & & \\
Pielou's & & & & & & & & & & \\
Nest & 0.76 & 0.03 & 1.00 & 1.50 & 0.230 & 0.63 & 0.12 & 1.00 & 4.06 & 0.053 \\
Ref. soils & 0.77 & 0.04 & & & & 0.70 & 0.06 & & & \\
\hline
\end{tabular}

Based on the Bray-Curtis distances, the bacterial communities showed a significant difference in their composition between the nest and the reference soils environments, for both OTUs and the more comprehensive T-RF data, across most pairs of nests and reference soils. (Fig. 1, Table 2). For both the OTUs and the T-RFs, environment explained most of the variation of the dissimilarities, followed by location (OTUs), and month and location (T-RFs), respectively. The effect of island was significant only for the OTUs, whereas the effect of month was significant only for the T-RFs (Table 2). The effect of island was, however, confounded by the effect of location, due to the nested nature of the data. 

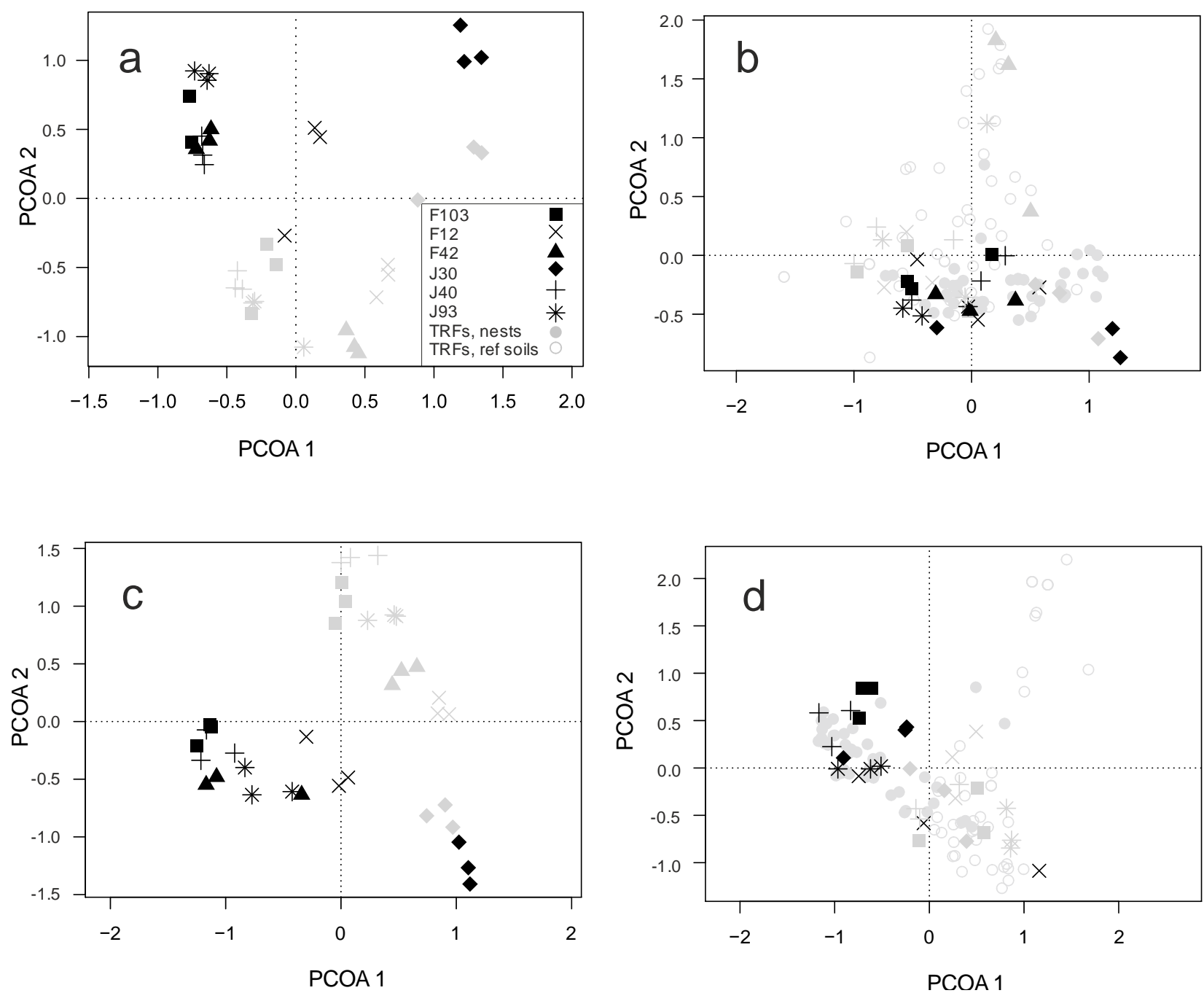

Figure 1. Distribution of nests and reference soil communities according to Principal Coordinates analysis, (a) bacterial OTUs, $n=36$, (b) bacterial T-RFs, $n=127$, (c) fungal OTUs, $n=36$, and (d) fungal $T$ RFs, $\mathbf{n = 1 2 1}$. Different symbols represent the locID of each nest sample and corresponding reference soil sample.For the OTU data and the corresponding samples in the T-RF data, black symbols indicate the nest environment, and corresponding grey symbols indicate the reference soil environment. The closed grey circles represent the remaining T-RF samples of the nests, and the open grey circles represent the ones of the reference soils. The letters $\mathrm{F}$ and $\mathrm{J}$ indicate the name of the island (Furuskär or Joskär).

The network analysis also demonstrated a clear clustering according to environment and location, across all three months of sampling (Fig. 2), with low centralization (range 0.0830.13) and high clustering (range 0.736-0.777), typical for a modular structure (Table S2). This suggests that communities in each environment and location assemble and function in similar ways. The Pareto-Lorenz curves of both the nests and the reference soil environment were similarly shaped, but the $F o$ value for the nest environment was slightly higher $(0.92)$ than that for the reference soils (0.89) (Fig. 3). 
Table 2. PERMANOVA test of the effects of environment (nest or reference soils), month, island and locID (location of nest and corresponding reference soil sample) on the Bray-Curtis distances of the microbial OTU and T-RF data. Bold face values are significant at $\mathrm{p}<0.05$.

\begin{tabular}{lllllllll}
\hline & OTUs & \multicolumn{5}{c}{ T-RFs } \\
Test effect & $F$ & $d f$ & $R 2$ & $p$ & $F$ & $d f$ & $R 2$ & $p$ \\
\hline \multirow{3}{*}{ environment } & BACTERIA & & & & & & \\
month & 7.32 & 30 & 0.158 & $\mathbf{0 . 0 0 1}$ & 18.55 & 120 & 0.118 & $\mathbf{0 . 0 0 1}$ \\
island & 0.9 & 30 & 0.019 & 0.491 & 7.62 & 120 & 0.048 & $\mathbf{0 . 0 0 1}$ \\
locID & 2.53 & 30 & 0.055 & $\mathbf{0 . 0 1 4}$ & 1.57 & 120 & 0.010 & 0.131 \\
& 4.84 & 30 & 0.105 & $\mathbf{0 . 0 0 1}$ & 2.99 & 120 & 0.019 & $\mathbf{0 . 0 0 9}$ \\
environment & FUNGI & & & & & & \\
month & 5.22 & 30 & 0.124 & $\mathbf{0 . 0 0 1}$ & 15.14 & 114 & 0.109 & $\mathbf{0 . 0 0 1}$ \\
island & 0.59 & 30 & 0.014 & 0.950 & 1.09 & 114 & 0.008 & 0.329 \\
locID & 2.46 & 30 & 0.058 & $\mathbf{0 . 0 0 3}$ & 2.46 & 114 & 0.018 & $\mathbf{0 . 0 0 2}$ \\
\hline
\end{tabular}
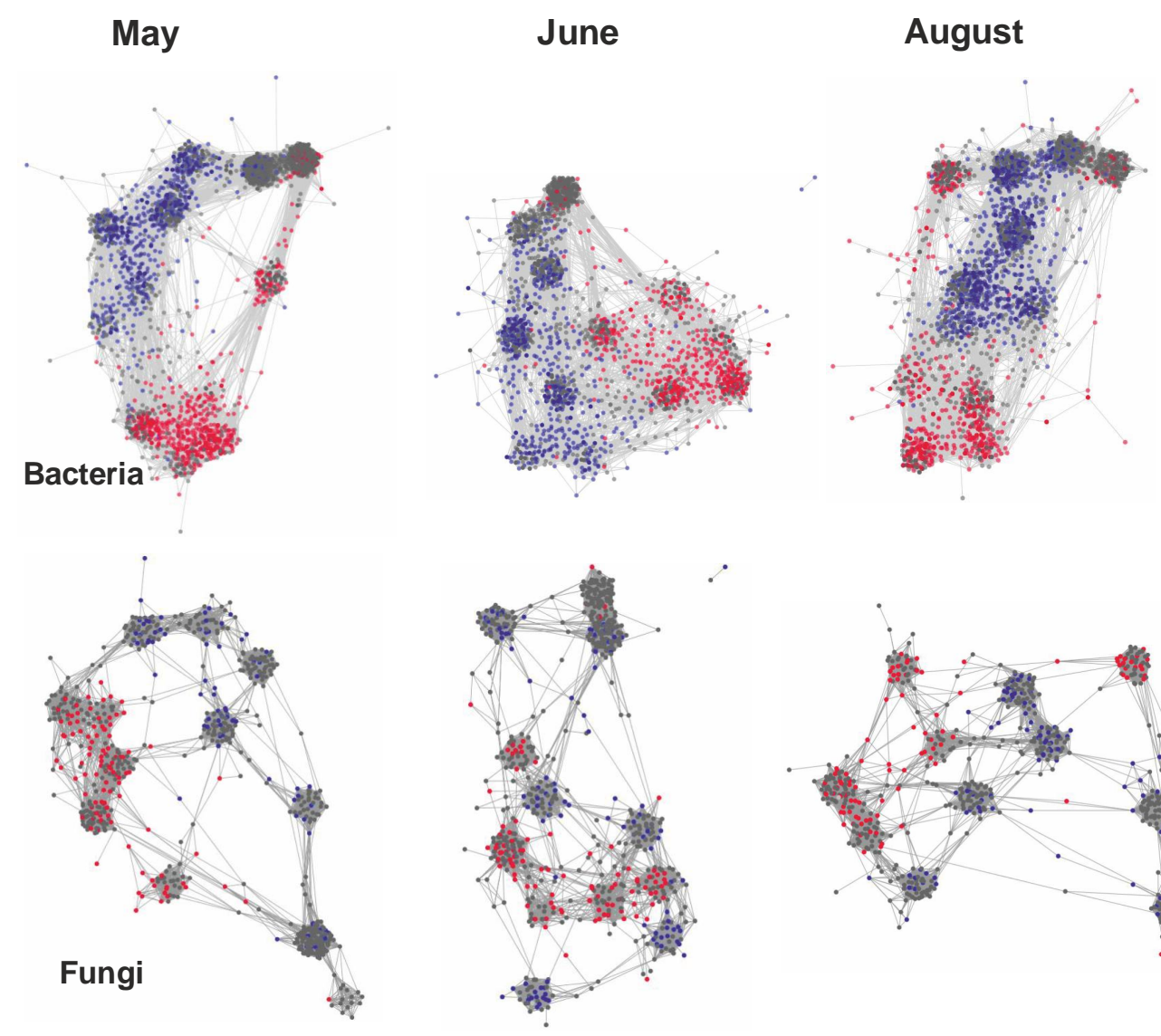

Figure 2. Monthly networks of nests and reference soils, constructed for bacteria and fungi (n=36). Red dots correspond to indicator OTUs in the nest environment, and blue dots to indicator OTUs is the reference soils. All other OTUs are coloured grey. 

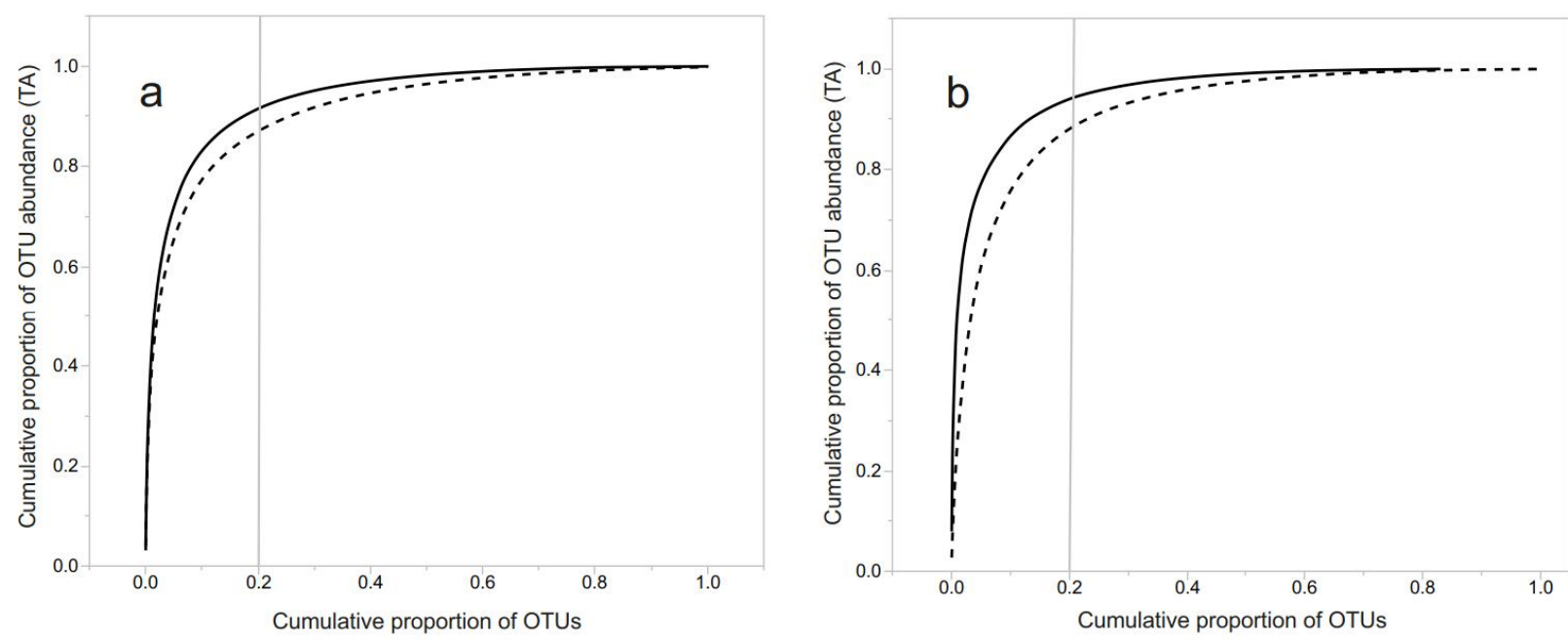

Figure 3. Functional organization (Fo) according to the Pareto-Lorenz curves of bacterial (a) and fungal (b) OTUs $(\mathbf{n = 3 6})$. The continuous black line represents the nest communities, the dashed line represents the communities of the reference soils. The $F o$ value equals the value projected at the y-axis, where the critical $20 \%$ at the $\mathrm{x}$-axis (grey continuous line) intercepts with the Pareto-Lorenz curves.

\subsubsection{Taxon distributions, indicator taxa, and core indicators}

Eighteen different bacterial phyla were identified, covering $96 \%$ of the OTUs. Sixteen of these were present in the nest samples, and all 18 in the reference soils (Table 3). The four most abundant ones, Proteobacteria, Actinobacteria, Acidobacteria and Bacteroidetes, represented $91.3 \%$ of the total rarefied read abundance (total abundance). The remaining phyla represented $4.7 \%$ of the total abundance, whereas $4.0 \%$ remained unidentified at the level of phylum (Table 3).

We identified $51.2 \%$ of the total abundance to the level of genus, encompassing 266 different genera. Twenty-eight of these were significantly more abundant in the nest environment, and 47 were more abundant in the reference soils (Table S3). Of the most abundant genera (covering more than $0.9 \%$ of the total abundance), the Burkholderia and Mycobacterium were significantly more abundant in the nest environment, whereas the Acidobacteria Gp1, Gp2, Caulobacter, and Rhizomicrobium were more abundant in the reference soils.

Of the 5579 bacterial OTUs, 181 (15.51\% of the total abundance) were classified as indicator taxa for the nest, and 288 (17.44\% of the total abundance) for the reference soils. The indicator values ranged between 0.63 and 1 (Table S4). Of these were 72 OTUs, representing seven phyla, further classified as core indicators, 35 for the nest environment (3.74\% of the total abundance), and 37 for the reference soils (4.43\% of the total abundance) (Table 4). Two phyla (Actinobacteria and Cyanobacteria) were characterized as containing core indicators for the nest environment, whereas core indicators belonging to four phyla (Armatimonadetes, Bacteroidetes, Planctomycetes, and Verrucomicrobia) were absent in the nest environment, but present in the reference soils (Table 4). Lower taxa belonging to Acidobacteria and Proteobacteria were identified as core indicators for both environments. 
Table 3. Comparison of read abundance in nests and reference soils of bacterial and fungal phyla, presented as percentages of the total abundance across both environments. Bold face values are significant at $\mathrm{p}<0.05$.

\begin{tabular}{|c|c|c|c|c|c|c|}
\hline & Nest & $\begin{array}{l}\text { Reference } \\
\text { soils }\end{array}$ & $F$ & $p$ & $\begin{array}{l}\text { No. of id } \\
\text { In nests }\end{array}$ & $\begin{array}{l}\text { ntified genera } \\
\text { In ref. soils }\end{array}$ \\
\hline \multicolumn{7}{|l|}{ BACTERIAL phyla: } \\
\hline Acidobacteria & 9.49 & 10.94 & 2.63 & 0.116 & 13 & 15 \\
\hline Actinobacteria & 13.41 & 7.67 & 9.20 & 0.005 & 65 & 61 \\
\hline Armatimonadetes & 0.55 & 0.56 & 0.01 & 0.929 & 4 & 4 \\
\hline Bacteroidetes & 2.80 & 3.65 & 2.47 & 0.127 & 28 & 30 \\
\hline $\mathrm{BRC} 1$ & 0.0002 & 0.01 & 6.38 & 0.017 & 1 & 1 \\
\hline Chloroflexi & 0.05 & 0.06 & 0.22 & 0.641 & 5 & 5 \\
\hline Cyanobacteria/Chloroplast & 0.63 & 0.07 & 11.17 & 0.002 & 4 & 3 \\
\hline Firmicutes & 0.25 & 0.32 & 0.31 & 0.580 & 13 & 10 \\
\hline Gemmatimonadetes & 0.16 & 0.35 & 8.47 & 0.007 & 1 & 1 \\
\hline Nitrospira & 0.00009 & 0.01 & 1.41 & 0.244 & 1 & 1 \\
\hline OD1 & 0.0001 & 0.0003 & 0.71 & 0.407 & 1 & 1 \\
\hline Planctomycetes & 0.10 & 0.26 & 14.76 & 0.001 & 6 & 6 \\
\hline Proteobacteria & 20.52 & 22.83 & 3.30 & 0.080 & 103 & 104 \\
\hline Spirochaetes & - & 0.02 & & & & 1 \\
\hline SR1 & - & 0.0016 & & & & 1 \\
\hline Tenericutes & 0.0015 & 0.0011 & 0.08 & 0.779 & 2 & 1 \\
\hline TM7 & 0.33 & 0.25 & 1.01 & 0.323 & 1 & 1 \\
\hline Verrucomicrobia & 0.11 & 0.58 & 40.96 & 0.001 & 3 & 3 \\
\hline Not identified & 1.59 & 2.41 & 8.5 & 0.007 & & \\
\hline Total & 100 & & & & 251 & 249 \\
\hline \multicolumn{7}{|l|}{ FUNGAL phyla: } \\
\hline Ascomycota & 46.84 & 38.12 & 29.46 & 0.001 & 118 & 114 \\
\hline Basidiomycota & 1.58 & 6.67 & 25.5 & 0.001 & 35 & 46 \\
\hline Chytridiomycota & 0.01 & 0 & 1.07 & 0.309 & 2 & 2 \\
\hline Glomeromycota & - & 0.05 & & & & 1 \\
\hline Mucoromycota & 0.16 & 0.17 & 0.03 & 0.866 & 5 & 4 \\
\hline Not identified & 1.42 & 4.98 & 14.76 & 0.001 & & \\
\hline Total & 100 & & & & 160 & 167 \\
\hline
\end{tabular}

Eight of the core indicators for the nest environment were identified to the level of genus, four Actinobacteria (Actinomycetospora, Frondihabitans, Pseudonocardia, and Streptomyces), three Proteobacteria (Burkholderia, Brevundimonas, and Methylobacterium), and one Cyanobacteria (Chloroplasts). Five genera were identified as core indicators for the reference soils, one each of Armatimonadetes (Gp5), Bacteroidetes (Ferruginibacter), Planctomycetes (Zavarzinella), Proteobacteria (Acidisphaera), and Verrucomicrobia (Opitutus) (Table 4). For Acidobacteria, Gp2, 
Gp3, and Gp5 were identified as core indicators for the reference soils only, whereas Gp1 remained as representative of both environments (Table 4). All core indicators identified at the level of genus, with the exception of Streptomyces, corresponded with the significantly more abundant genera in their respective environment (Table S3).

Table 4. The bacterial and fungal core indicators; the number of OTUs, reads and percentage of the total abundance they represent.

\begin{tabular}{|c|c|c|c|c|c|c|c|c|c|c|}
\hline \multirow{3}{*}{ Phylum } & \multicolumn{5}{|l|}{ Nest environment } & \multicolumn{5}{|c|}{ Reference soil environment } \\
\hline & Taxon & Level & OTUs & Reads & $\begin{array}{l}\% \text { of tot } \\
\text { abund. }\end{array}$ & Taxon & Level & OTUs & Reads & $\begin{array}{l}\% \text { of tot } \\
\text { abund. }\end{array}$ \\
\hline & BACTERIA & & & & & & & & & \\
\hline Acidobacteria & Acidobacteria_Gp1 & n.a. & 2 & 13878 & 1.21 & Acidobacteria_Gp1 & n.a. & 5 & 24263 & 2.11 \\
\hline Acidobacteria & & & & & & Acidobacteria_Gp2 & n.a. & 3 & 2882 & 0.25 \\
\hline Acidobacteria & & & & & & Acidobacteria_Gp3 & n.a. & 4 & 1630 & 0.14 \\
\hline Acidobacteria & & & & & & Acidobacteria_Gp5 & n.a. & 1 & 121 & 0.01 \\
\hline Actinobacteria & Actinobacteria & Class & 1 & 369 & 0.03 & & & & & \\
\hline Actinobacteria & Actinomycetales & Order & 6 & 3610 & 0.31 & & & & & \\
\hline Actinobacteria & Microbacteriaceae & Family & 3 & 1563 & 0.14 & & & & & \\
\hline Actinobacteria & Frondihabitans & Genus & 2 & 696 & 0.06 & & & & & \\
\hline Actinobacteria & Actinomycetospora & Genus & 1 & 874 & 0.08 & & & & & \\
\hline Actinobacteria & Pseudonocardia & Genus & 1 & 541 & 0.05 & & & & & \\
\hline Actinobacteria & Streptomyces & Genus & 1 & 1606 & 0.14 & & & & & \\
\hline Cyanobacteria & Chloroplast & Genus & 1 & 259 & 0.02 & & & & & \\
\hline Armatimonadetes & & & & & & Armatimonadetes Gp5 & n.a. & 1 & 180 & 0.02 \\
\hline Bacteroidetes & & & & & & Bacteroidetes & Phylum & 1 & 210 & 0.02 \\
\hline Bacteroidetes & & & & & & Chitinophagaceae & Family & 2 & 3516 & 0.31 \\
\hline Bacteroidetes & & & & & & Ferruginibacter & Genus & 1 & 203 & 0.02 \\
\hline Planctomycetes & & & & & & Planctomycetaceae & Family & 1 & 76 & 0.01 \\
\hline Planctomycetes & & & & & & Zavarzinella & Genus & 1 & 93 & 0.01 \\
\hline Proteobacteria & Alphaproteobacteria & Class & 1 & 831 & 0.07 & Alphaproteobacteria & Class & 3 & 3810 & 0.33 \\
\hline Proteobacteria & Rhizobiales & Order & 4 & 4123 & 0.36 & Rhizobiales & Order & 3 & 3324 & 0.29 \\
\hline Proteobacteria & Methylobacterium & Genus & 2 & 2529 & 0.22 & & & & & \\
\hline Proteobacteria & Acetobacteraceae & Family & 4 & 3755 & 0.33 & Acetobacteraceae & Family & 1 & 288 & 0.03 \\
\hline Proteobacteria & & & & & & Acidisphaera & Genus & 1 & 610 & 0.05 \\
\hline Proteobacteria & Caulobacteraceae & Family & 1 & 287 & 0.02 & & & & & \\
\hline Proteobacteria & Brevundimonas & Genus & 1 & 2443 & 0.21 & & & & & \\
\hline Proteobacteria & & & & & & Burkholderiales & Order & 1 & 265 & 0.02 \\
\hline Proteobacteria & Burkholderiaceae & Family & 1 & 447 & 0.04 & & & & & \\
\hline Proteobacteria & Burkholderia & Genus & 2 & 5003 & 0.44 & & & & & \\
\hline Proteobacteria & & & & & & Deltaproteobacteria & Class & 1 & 156 & 0.01 \\
\hline Proteobacteria & & & & & & Gammaproteobacteria & Class & 2 & 7335 & 0.64 \\
\hline Verrucomicrobia & & & & & & Opitutus & Genus & 3 & 1631 & 0.14 \\
\hline Not identified & & & 1 & 147 & 0.01 & & & 2 & 334 & 0.03 \\
\hline Total & & Tot. & 35 & 42961 & 3.74 & & & 37 & 50927 & 4.43 \\
\hline
\end{tabular}




\begin{tabular}{|c|c|c|c|c|c|c|c|c|c|c|}
\hline & FUNGI & & & & & & & & & \\
\hline Ascomycota & Ascomycota & Phylum & 3 & 3948 & 1.54 & Ascomycota & Phylum & 3 & 2250 & 0.88 \\
\hline Ascomycota & Coniochaetaceae & Family & 1 & 250 & 0.10 & & & & & \\
\hline Ascomycota & Dothioraceae & Family & 1 & 1646 & 0.64 & & & & & \\
\hline Ascomycota & Exophiala & Genus & 1 & 291 & 0.11 & & & & & \\
\hline Ascomycota & Oidiodendron & Genus & 2 & 4538 & 1.77 & & & & & \\
\hline Ascomycota & Scleroconidioma & Genus & 1 & 349 & 0.14 & & & & & \\
\hline Ascomycota & & & & & & Helotiales & Order & 1 & 56 & 0.02 \\
\hline Ascomycota & & & & & & Calycina & Genus & 1 & 206 & 0.08 \\
\hline Ascomycota & & & & & & Pochonia & Genus & 1 & 214 & 0.08 \\
\hline Mucoromycota & Umbelopsis & Genus & 1 & 286 & 0.11 & Mortierella & Genus & 1 & 84 & 0.03 \\
\hline Total & & Tot. & 10 & 11308 & 4.40 & & & 7 & 2810 & 1.09 \\
\hline
\end{tabular}

\subsection{Fungi}

Illumina sequencing generated a total of fungal 894469 reads, $60 \%$ of which originated from the nests (Table S1). The reads clustered into 1854 OTUs, 1494 of which were found in the nest samples, 1625 in reference soils, and 1265 were shared between the two environments. Of these 229 OTUs were unique to the nests, and 360 unique to the reference soils, respectively. Neither the number of OTUs, nor the levels of diversity and evenness differed significantly between the nests, and the reference soils (Table 1). The T-RFLP analysis using MspI, generated 132 T-RFs from the soil samples, and 131 from the reference soils.

The Bray-Curtis distances in the nests differed significantly from the ones in the reference soils, both for OTUs and T-RFs. The effect of location on the dissimilarities of the communities was also significant, but confounded, as in the case of bacteria (Fig. 1, Table 2). The network analysis also showed a clear clustering according to environment and location (Fig 2), with high clustering values, ranging from $0.809-0.851$, and low network centralities, ranging from 0.089-0.128 (Table S2). This suggests highly decentralized and modular network topologies, and similar structures of the communities in the two environments. The Pareto-Lorenz curves signalled high $F o$ values for both environments (0.92 and 0.88 for nests, and soils, respectively) (Fig. 3).

\subsubsection{Taxon distributions, indicator taxa, and core indicators}

Five fungal phyla were identified, covering 93.6\% of the total abundance. Four of these, (Ascomycota, Basidiomycota, Chytridiomycota and Mucoromycota) were present in both environments, and one, Glomeromycota, only in reference soils (Table 3). The two most common phyla, Ascomycota and Basidiomycota accounted for $93.2 \%$ of the total abundance, whereas the remaining three phyla each represented less than $1 \%$ of the reads. (Table 3 ). We identified $41.0 \%$ of the total abundance to the level of genus, encompassing 181 genera. Fifteen of these were significantly more abundant in the nest environment, and 24 in the reference soils (Table S5). Of the most abundant genera (covering more than $0.7 \%$ of the total abundance), the genera Cladophialophora, Oidiodendron and Thelebolus were significantly more abundant in the nest environment, whereas Meliniomyces and Piloderma were more abundant in the reference soils. 
Of the 1854 fungal OTUs, 31 (17.19\% of the total abundance) were classified as indicator taxa for the nest, and 16 (2.01\% of the total abundance) for the reference soils. The indicator values ranged between 0.67 and 1 (Table S6). Of these 17 OTUs, representing two phyla, Ascomyota and Mucoromycota, were further classified as core indicators, 10 for the nest environment (4.4\% of the total abundance), and seven for the reference soils (1.09\% of the total abundance). Four of the core indicators for the nest environment were identified to the level of genus, three in the phylum Ascomycota (Exophiala, Oidiodendron and Scleroconidioma), and one in Mucoromycota (Umbelopsis) (Table 4). For the reference soils, three core indicators were identified to the level of genus, two in Ascomycota (Calycina and Pochonia), and one in Mucoromycota (Mortierella) (Table 4). All core indicators identified to the level of genus, were also significantly more abundant in their respective environment (Table S5).

\section{Discussion}

In this study, we characterized the bacterial and fungal communities in the nest mounds of the ant $F$ exsecta and in the reference soils. We found that the nest environment, which is largely shaped by its inhabitants, harbours bacterial and fungal communities that are distinct from the surrounding top soil. As a whole, the enrichment of certain taxa could be distinguished already at the level of phylum, such as Actinobacteria and Ascomycota in the nests, or Basidiomycota and Verrucomicrobia in the reference soils. On lower taxonomic levels, we found significant differences in the community assembly of both bacteria and fungi between the two environments, suggesting different functional associations, based on the taxon-specific traits affiliated with the microbes in question. In particular, the nest-characteristic core indicators contained several potential Actinobacterial ant symbionts, whereas no potential ant-symbiotic taxa were seen among the most characteristic taxa in the reference soils.

Both the bacterial and the fungal nest communities of $F$. exsecta mounds were highly distinct from the reference soils throughout the sampling season, yet showed considerable similarity across the nest environments, regardless of location. This was clearly visible in the results of both the NGS and the more extensive T-RFLP data, rendering strong support for our hypothesis of dissimilar microbial communities in the nests compared to those in the reference soils. The network analysis provided further support for the hypothesis, as the nest environments formed modular sub-networks, largely separated from the reference soil networks, both for bacteria and fungi across the three sampling events. These results largely agree with earlier studies on intra-nest microbial communities of other ant species in other climatic zones, both for bacterial (Boots et al., 2012; Kellner et al., 2015; Lucas et al., 2017), and fungal communities (Boots and Clipson, 2013). We also found secondary effects of island, and the physical location of nests and corresponding reference soils. This was most likely due to differences in soil type and vegetation between the locations of each nest/reference soil pair. An evaluation of the reciprocal importance of location and island cannot be done, as these two effects are confounded, due to the nested structure of the study.

The functional organization of the communities indicated dominance by a few species in both the nest environment, and the reference soils. This can decisively reduce the resilience of a community, when resilience is defined as the tendency of a community to return to its original functional state before disturbance (Marzorati et al., 2008; Pimm, 1984; Shade et al., 2012; Wittebolle et al., 2009). Our analysis should, however, only be considered as a broad characterization of the functional 
organization within the communities, as these consist of many taxonomically different, but functionally similar microbes (Burke et al., 2011). In some communities, function is linked with microbial composition, but not in others (Shade and Handelsman, 2012). Hence, a thorough evaluation of the resilience of the microbial organisation according to function or traits, and their variation between the nests and the reference soils, would require a separate study.

The abundance of several phyla differed significantly between the nests, and the reference soils, although most phyla were present in both environments. All the identified bacterial taxa, both in nests and reference soils, were typical of oligotrophic, moderately acidic soils of coniferous forests, in particular the most abundant Acidobacteria, Actinobacteria, and Proteobacteria (Baldrian et al., 2012). The abundances of these phyla vary considerably in forest soils, depending on soil components (Baldrian et al., 2012; Sietiö et al., 2018). The enrichment of Actinobacteria and Ascomycota in the nests may be due to activities of the ants, whereas the phylum Glomeromycota was detected only in the reference soils, likely because these mycorrhiza forming fungi prefer the plant rhizosphere (Young, 2012).

The indicators represented broadly the bacterial and fungal genera, which were enriched in the environment in question. Overall, our results were in agreement with earlier studies on soil microbes, both with respect to the number and taxonomy of the indicators, e.g. (Bach et al., 2018; Leff et al., 2018). Interestingly, we found that the fungal indicators of the nest environment covered $17.19 \%$ of the total abundance, whereas the reference soil indicators covered only $2.01 \%$ of the total abundance. By contrast, the corresponding difference for the bacterial indicators was negligible $(15.51 \%$ vs. $17.44 \%$ ). The higher percentage of total abundance covered by fungal nest indicators may be attributable to the high concentration of recalcitrant, coniferous litter in the nests, which is expected to attract fungal decomposers over bacterial ones (Haňáčková et al., 2015; Vořr̂šková and Baldrian, 2013). Hence, the reference soils would not be expected to contain such stable clusters of specialized fungal decomposers.

Those indicator taxa, which were consistently present throughout the sampling period in either the nests or the reference soils, were identified as core indicators of their respective environment. Several of the bacterial core indicators of the nests encompassed taxa, which are significantly associated with, or symbiotic to, ants, such as the bacterial genera Pseudonocardia (Folgarait et al., 2011), Streptomyces (Sen et al., 2009) Burkholderia, Methylobacterium (Van Borm et al., 2002), and Brevundimonas (Jaffe et al., 2001), as well as the fungal core indicator Exophiala (Duarte et al., 2014). These may represent members of the microbiome that forms symbiotic relationships with the ants. The remaining core indicators of the nest, the three bacterial genera, Frondihabitans (Han et al., 2016), Methylobacterium (Pirttila et al., 2000), and Cyanobacteria/Chloroplast (Aschenbrenner et al., 2016), and three fungal genera, Oidiodendron, Scleroconidioma (Davey and Currah, 2006), and Umbelopsis (Santalahti et al., 2016), are frequently found in pine and spruce needles, moss and lichen (Laakso and Setala, 1998; Lenoir et al., 2003b; Littlewood and Young, 2008), and may thus owe their presence in the nest to the nest material.

In the reference soil, the bacterial core indicators suggested associations with the rhizosphere, (Ferruginibacter, Timonen et al., 2017), with acidic environments, (Acidisphaera, Hiraishi et al., 2000), Spaghnum moss (Zavarzinella, Kulichevskaya et al., 2009), or plant roots (the fungal core indicator Calycina, Addy et al., 2005). The bacterium Opitutus, here classified as a core indicator of 
the reference soils, but has also been found in association with Cephalotes ants (Kautz et al., 2013). Interestingly, the core indicators of the reference soils also encompassed the potentially entomopathogenic genera Pochonia (Lin et al., 2018), and Mortierella (Vega et al., 2012), which were mainly absent from the nests. This begs the question whether the nest environment and the ants represent a hostile environment to these fungi. Acidobacteria $\mathrm{Gp} 1$ was the only taxon, which was a core indicator of both the nest and the reference soil. This signals functional specificity at taxonomic levels lower than the ones we could identify in this study, such as species or strain level. The Gp1 has a broad range of enzymes related to sugar usage compared to other Acidobacterial groups (Kielak et al., 2016). Nests containing surplus honeydew (Jílková et al., 2018) may therefore favour the growth of certain specialized strains of Gp1, compared to the reference soils, where the resources are more diverse.

\section{Conclusions}

Taken together, the results support our hypothesis that the bacterial and fungal communities in the nests of mound-building ants are highly distinct compared to surrounding soils, regarding the community composition, but also regarding the enrichment of taxa. Furthermore, also in accordance with our hypothesis, we identified a small, but consistent, set of core indicators that encompass the potential core microbiome of the nest mounds. A core microbiome (sensu Shade and Handelsman, 2012) is a set of stable and consistent microbes shared across similar habitats, hypothesized to play a key role within the habitat. The presence of such a distinct and consistent microbiome, inside a shielded and constantly maintained environment, suggests a highly adapted microbial community (Koskella and Vos, 2015). Several of the core indicators of the nests were typical of the litter-based (Laakso and Setala, 1998) nest soil, but some of the taxa we identified may be associated specifically with ants. We found no such patterns in the reference soils, as these were mainly enriched in taxa typical of the rhizosphere. Thus, our results suggest potential candidates for further studies, especially the Actinobacteria, and lower taxa therein.

Characterizing the core members of the community is crucial to understand which taxa play a pivotal role in ecosystem functions. Except for leaf-cutting ants (e.g. (Currie, 2001; Sen et al., 2009), the microbes dwelling in ant nests are virtually uncharted, especially with respect to their variation in time and space, and in comparison with the surrounding soils. Our results show that the nest environment, which is rigorously curated and maintained by its host, provides an environment, where microbial species can adapt and diverge from the communities in the surrounding soils. Thus, our results contribute to our understanding of the composition and function of microbiomes in fragmented habitats, and suggests further avenues of exploration on microbes and their adaptation in secluded environments.

\section{Data accessibility}

The unprocessed sequences are available at NCBI Sequence Read Archive, Bioproject number PRJNA399258. 


\section{Acknowledgements}

This work was funded by the Academy of Finland (grant numbers 252411 and 284666).

We thank our technician Heini Ali-Kovero for her input during the laboratory assays, and Claire Morandin for her assistance with the bioinformatics.

\section{References}

Addy, H.D., Piercey, M.M., Currah, R.S., 2005. Microfungal endophytes in roots. Canadian Journal of Botany 83, 113. doi:10.1139/b04-171

Aschenbrenner, I.A., Cernava, T., Berg, G., Grube, M., 2016. Understanding microbial multi-species symbioses. Frontiers in Microbiology 7, 1-9. doi:10.3389/fmicb.2016.00180

Bach, E.M., Williams, R.J., Hargreaves, S.K., Yang, F., Hofmockel, K.S., 2018. Greatest soil microbial diversity found in micro-habitats. Soil Biology and Biochemistry 118, 217-226. doi:10.1016/j.soilbio.2017.12.018

Baird, R., Woolfolk, S., Watson, C.E., 2007. Survey of Bacterial and Fungal Associates of Black/Hybrid Imported Fire Ants from Mounds in Mississippi. Southeastern Naturalist 6, 615-632. doi:10.1656/15287092(2007)6[615:SOBAFA]2.0.CO;2

Baldrian, P., Kolařík, M., Stursová, M., Kopecký, J., Valášková, V., Větrovský, T., Zifčáková, L., Snajdr, J., Rídl, J., Vlček, C., Vořŕšková, J., 2012. Active and total microbial communities in forest soil are largely different and highly stratified during decomposition. The ISME Journal 6, 248-58. doi:10.1038/ismej.2011.95

Barnard, R.L., Osborne, C.A., Firestone, M.K., 2013. Responses of soil bacterial and fungal communities to extreme desiccation and rewetting. ISME Journal 7, 2229-2241. doi:10.1038/ismej.2013.104

Boots, B., Clipson, N., 2013. Linking ecosystem modification by the yellow meadow ant (Lasius flavus) to microbial assemblages in different soil environments. European Journal of Soil Biology 55, 100-106. doi:10.1016/j.ejsobi.2013.01.002

Boots, B., Keith, A.M., Niechoj, R., Breen, J., Schmidt, O., Clipson, N., 2012. Unique soil microbial assemblages associated with grassland ant species with different nesting and foraging strategies. Pedobiologia 55, 33-40. doi:10.1016/j.pedobi.2011.10.004

Burke, C., Thomas, T., Lewis, M., Steinberg, P., Kjelleberg, S., 2011. Composition, uniqueness and variability of the epiphytic bacterial community of the green alga Ulva australis. ISME Journal 5, 590-600. doi:10.1038/ismej.2010.164

Cáceres, M. De, Legendre, P., 2009. Associations between species and groups of sites:Inindices and statistical inference. Ecology 90, 3566-3574. doi:10.1890/08-1823.1

Castro, H.F., Classen, A.T., Austin, E.E., Norby, R.J., Schadt, C.W., 2010. Soil microbial community responses to multiple experimental climate change drivers. Applied and Environmental Microbiology 76, 999-1007. doi:10.1128/AEM.02874-09

Chung, J., Ha, E.-S., Park, H.-R., Kim, S., 2004. Isolation and characterization of Lactobacillus species inhibiting the formation of Streptococcus mutans biofilm. Oral Microbiology and Immunology 19, 214-216. doi:10.1111/j.0902-0055.2004.00137.x

Culman, S.W., Bukowski, R., Gauch, H.G., Cadillo-Quiroz, H., Buckley, D.H., 2009. T-REX: software for the processing and analysis of T-RFLP data. Bmc Bioinformatics 10, 171. doi:10.1186/1471-2105-10-171

Currie, C.R., 2001. A Community of Ants, Fungi, and Bacteria: A Multilateral Approach to Studying Symbiosis. Annual Review of Microbiology 55, 357-380. doi:10.1146/annurev.micro.55.1.357

Czechowski, W., Radchenko, A., Czhechowska, W., 2002. The Ants (Hymenoptera, Formicidae) of Poland. Museum of Institute of Zoology. 
Dauber, J., Schroeter, D., Wolters, V., 2001. Species Specific Effects of Ants on Microbial Activity and N- Availability in the Soil of an Old-Field. European Journal of Soil Biology 37, 259-261. doi:10.1016/S1164-5563(01)01094-9

Davey, M.L., Currah, R.S., 2006. Interactions between mosses (Bryophyta) and fungi. Canadian Journal of Botany 84, 1509-1519. doi:10.1139/b06-120

Dignac, M.F., Derrien, D., Barré, P., Barot, S., Cécillon, L., Chenu, C., Chevallier, T., Freschet, G.T., Garnier, P., Guenet, B., Hedde, M., Klumpp, K., Lashermes, G., Maron, P.A., Nunan, N., Roumet, C., Basile-Doelsch, I., 2017. Increasing soil carbon storage: mechanisms, effects of agricultural practices and proxies. A review. Agronomy for Sustainable Development. doi:10.1007/s13593-017-0421-2

Domisch, T., Ohashi, M., Finer, L., Risch, A.C., Sundström, L., Kilpeläinen, J., Niemela, P., 2008. Decomposition of organic matter and nutrient mineralisation in wood ant (Formica rufa group) mounds in boreal coniferous forests of different age. Biology and Fertility of Soils 44, 539-545. doi:10.1007/s00374-007-0248-0

Dostál, P., Březnová, M., Kozlíčková, V., Herben, T., Kovář, P., 2005. Ant-induced soil modification and its effect on plant below-ground biomass. Pedobiologia 49, 127-137. doi:10.1016/j.pedobi.2004.09.004

Duarte, A.P.M., Attili-Angelis, D., Baron, N.C., Forti, L.C., Pagnocca, F.C., 2014. Leaf-cutting ants: An unexpected microenvironment holding human opportunistic black fungi. Antonie van Leeuwenhoek, International Journal of General and Molecular Microbiology 106, 465-473. doi:10.1007/s10482-014-0215-3

Dufrêne, M., Legendre, P., 1997. Species assemblages and indicator species: The need for a flexible asymmetrical approach. Ecological Monographs 67, 345-366. doi:10.2307/2963459

Edgar, R.C., 2013. UPARSE: highly accurate OTU sequences from microbial amplicon reads. Nature Methods 10, 9968. doi:10.1038/nmeth.2604

Edwards, U., Rogall, T., Blöcker, H., Emde, M., Böttger, 1989. Isolation and direct complete nucleotide determination of entire genes. Characterization of a gene coding for 16S ribosomal RNA. Nucleic Acids Research 17, 78437853. doi:10.1093/nar/17.19.7843

Faust, K., Lahti, L., Gonze, D., de Vos, W.M., Raes, J., 2015. Metagenomics meets time series analysis: Unraveling microbial community dynamics. Current Opinion in Microbiology 25, 56-66. doi:10.1016/j.mib.2015.04.004

Folgarait, P., Gorosito, N., Poulsen, M., Currie, C.R., 2011. Preliminary in vitro insights into the use of natural fungal pathogens of leaf-cutting ants as biocontrol agents. Current Microbiology 63, 250-258. doi:10.1007/s00284-0119944-y

Frouz, J., Jilková, V., 2008. The effect of ants on soil properties and processes ( Hymenoptera : Formicidae ). Myrmecological News 11, 191-199.

Gardes, M., Bruns, T.D., 1993. ITS primers with enhanced specificity for basidiomycetes, application to the identification of mycorrihiza and rusts. Molecular Ecology. doi:Doi 10.1111/J.1365-294x.1993.Tb00005.X

Haag-Liautard, C., Vitikainen, E., Keller, L., Sundström, L., 2009. Fitness and the level of homozygosity in a social insect. Journal of Evolutionary Biology 22, 134-142. doi:10.1111/j.1420-9101.2008.01635.x

Han, S.R., Yu, S.C., Kang, S., Park, H., Oh, T.J., 2016. Complete genome sequence of Frondihabitans sp. strain PAMC28766, a novel carotenoid-producing and radiation-resistant strain isolated from an Antarctic lichen. Journal of Biotechnology 226, 20-21. doi:10.1016/j.jbiotec.2016.03.041

Haňáčková, Z., Koukol, O., Štursová, M., Kolař́́k, M., Baldrian, P., 2015. Fungal succession in the needle litter of a montane Picea abies forest investigated through strain isolation and molecular fingerprinting. Fungal Ecology 13, 157-166. doi:10.1016/j.funeco.2014.09.007

Hartmann, M., Niklaus, P.A., Zimmermann, S., Schmutz, S., Kremer, J., Abarenkov, K., Lüscher, P., Widmer, F., Frey, B., 2014. Resistance and resilience of the forest soil microbiome to logging-associated compaction. The ISME Journal 8, 226-44. doi:10.1038/ismej.2013.141

Hastings, A., Byers, J.E., Crooks, J.A., Cuddington, K., Jones, C.G., Lambrinos, J.G., Talley, T.S., Wilson, W.G., 2007. Ecosystem engineering in space and time. Ecology Letters 10, 153-164. doi:10.1111/j.1461-0248.2006.00997.x

Hawkes, C. V., Kivlin, S.N., Rocca, J.D., Huguet, V., Thomsen, M. a., Suttle, K.B., 2011. Fungal community responses to precipitation. Global Change Biology 17, 1637-1645. doi:10.1111/j.1365-2486.2010.02327.x 
Hiraishi, A., Matsuzawa, Y., Kanbe, T., Wakao, N., 2000. Acidisphaera rubrifaciens ge. nov., sp. nov., an aerobic bacteriochlorophyll-containing bacterium isolated from acidic environments 1539-1546.

Ihrmark, K., Bödeker, I.T.M., Cruz-Martinez, K., Friberg, H., Kubartova, A., Schenck, J., Strid, Y., Stenlid, J., Brandström-Durling, M., Clemmensen, K.E., Lindahl, B.D., 2012. New primers to amplify the fungal ITS2 region - evaluation by 454-sequencing of artificial and natural communities. FEMS Microbiology Ecology 82, 666-677. doi:10.1111/j.1574-6941.2012.01437.x

Ishak, H.D., Plowes, R., Sen, R., Kellner, K., Meyer, E., Estrada, D.A., Dowd, S.E., Mueller, U.G., 2011. Bacterial Diversity in Solenopsis invicta and Solenopsis geminata Ant Colonies Characterized by $16 \mathrm{~S}$ amplicon 454 Pyrosequencing. Microbial Ecology 61, 821-831. doi:10.1007/s00248-010-9793-4

Jaffe, K., Caetano, F.H., Sánchez, P., Hernández, J. V., Caraballo, L., Vitelli-Flores, J., Monsalve, W., Dorta, B., Lemoine, V.R., 2001. Sensitivity of ant Cephalotes colonies and individuals to antibiotics implies feeding symbiosis with gut microorganisms. Canadian Journal of Zoology 79, 1120-1124. doi:10.1139/cjz-79-6-1120

Jílková, V., Cajthaml, T., Frouz, J., 2018. Relative importance of honeydew and resin for the microbial activity in wood ant nest and forest floor substrate - a laboratory study. Soil Biology and Biochemistry 117, 1-4. doi:10.1016/j.soilbio.2017.11.002

Jílková, V., Cajthaml, T., Frouz, J., 2015. Respiration in wood ant (Formica aquilonia) nests as affected by altitudinal and seasonal changes in temperature. Soil Biology and Biochemistry 86, 50-57. doi:10.1016/j.soilbio.2015.03.024

Jílková, V., Frouz, J., 2014. Contribution of ant and microbial respiration to CO2 emission from wood ant (Formica polyctena) nests. European Journal of Soil Biology 60, 44-48. doi:10.1016/j.ejsobi.2013.11.003

Jílková, V., Šebek, O., Frouz, J., 2012. Mechanisms of pH change in wood ant (Formica polyctena) nests. Pedobiologia 55, 247-251. doi:10.1016/j.pedobi.2012.04.002

Jones, C.G., Lawton, J.H., Shachak, M., Organisms, M., 1994. Organisms as ecosystem engineers. Oikos 69, $373-386$.

Jouquet, P., Dauber, J., Lagerlöf, J., Lavelle, P., Lepage, M., 2006. Soil invertebrates as ecosystem engineers: Intended and accidental effects on soil and feedback loops. Applied Soil Ecology 32, 153-164. doi:10.1016/j.apsoil.2005.07.004

Jurgensen, M.F., Finér, L., Domisch, T., Kilpeläinen, J., Punttila, P., Ohashi, M., Niemelä, P., Sundström, L., Neuvonen, S., Risch, a. C., 2008. Organic mound-building ants: Their impact on soil properties in temperate and boreal forests. Journal of Applied Entomology 132, 266-275. doi:10.1111/j.1439-0418.2008.01280.x

Kadowaki, K., Sato, H., Yamamoto, S., Tanabe, A.S., Hidaka, A., Toju, H., 2014. Detection of the horizontal spatial structure of soil fungal communities in a natural forest. Population Ecology 56, 301-310. doi:10.1007/s10144013-0424-Z

Katzerke, A., Bliss, P., Moritz, R.F.A., 2010. Size matters: mole (Talpa europaea) hills and nest-site selection of the ant Formica exsecta. Population Ecology 52, 271-277. doi:10.1007/s10144-009-0180-2

Kautz, S., Rubin, B.E.R., Russell, J. A., Moreau, C.S., 2013. Surveying the microbiome of ants: Comparing 454 pyrosequencing with traditional methods to uncover bacterial diversity. Applied and Environmental Microbiology 79, 525-534. doi:10.1128/AEM.03107-12

Kellner, K., Ishak, H.D., Linksvayer, T.A., Mueller, U.G., 2015. Bacterial community composition and diversity in an ancestral ant fungus symbiosis. FEMS Microbiology Ecology 91, 1-10. doi:10.1093/femsec/fiv073

Kielak, A.M., Cipriano, A.P.M., Kuramae, E. E., 2016. Acidobacteria strains from subdivision 1 act as plant growthpromoting bacteria. Archives of Microbiology 198, 987-993. doi:10.1007/s00203-016-1260-2

Kilpeläinen, J., Finér, L., Niemelä, P., Domisch, T., Neuvonen, S., Ohashi, M., Risch, Sundström, L., 2007. Carbon, nitrogen and phosphorus dynamics of ant mounds (Formica rufa group) in managed boreal forests of different successional stages. Applied Soil Ecology 36, 156-163. doi:10.1016/j.apsoil.2007.01.005

King, J.R., 2016. Where do eusocial insects fit into soil food webs? Soil Biology \& Biochemistry 102, 55-62. doi:10.1016/j.soilbio.2016.07.019

Kõljalg, U., Nilsson, R.H., Abarenkov, K., Tedersoo, L., Taylor, A.F.S., Bahram, M., Bates, S.T., Bruns, T.D., Bengtsson-Palme, J., Callaghan, T.M., Douglas, B., Drenkhan, T., Eberhardt, U., Dueñas, M., Grebenc, T., 
Griffith, G.W., Hartmann, M., Kirk, P.M., Kohout, P., Larsson, E., Lindahl, B.D., Lücking, R., Martín, M.P., Matheny, P.B., Nguyen, N.H., Niskanen, T., Oja, J., Peay, K.G., Peintner, U., Peterson, M., Põldmaa, K., Saag, L., Saar, I., Schüßler, A., Scott, J.A., Senés, C., Smith, M.E., Suija, A., Taylor, D.L., Telleria, M.T., Weiss, M., Larsson, K.H., 2013. Towards a unified paradigm for sequence-based identification of fungi. Molecular Ecology 22, 5271-5277. doi:10.1111/mec.12481

Koskella, B., Vos, M., 2015. Adaptation in Natural Microbial Populations. Annual Review of Ecology, Evolution, and Systematics 46, 503-522. doi:10.1146/annurev-ecolsys-112414-054458

Kulichevskaya, I.S., Baulina, O.I., Bodelier, P.L.E., Rijpstra, W.I.C., Sinninghe Damsté, J.S., Dedysh, S.N., 2009. Zavarzinella formosa gen. nov., sp. nov., a novel stalked, Gemmata-like planctomycete from a Siberian peat bog. International Journal of Systematic and Evolutionary Microbiology 59, 357-364. doi:10.1099/ijs.0.002378-0

Laakso, J., Setälä, H., 1998. Composition and trophic structure of detrital food web in ant nest mounds of Formica aquilonia and in the surrounding forest soil. Oikos 81, 266-278. doi:10.2307/3547047

Lavelle, P., Decaëns, T., Aubert, M., Barot, S., Blouin, M., Bureau, F., Margerie, P., Mora, P., Rossi, J.P., 2006. Soil invertebrates and ecosystem services. European Journal of Soil Biology 42. doi:10.1016/j.ejsobi.2006.10.002

Leff, J.W., Bardgett, R.D., Wilkinson, A., Jackson, B.G., Pritchard, W.J., De Long, J.R., Oakley, S., Mason, K.E., Ostle, N.J., Johnson, D., Baggs, E.M., Fierer, N., 2018. Predicting the structure of soil communities from plant community taxonomy, phylogeny, and traits. ISME Journal 12, 1794-1805. doi:10.1038/s41396-018-0089-x

Legendre, P., Anderson, M.J., 1999. Distance-based redundancy analysis: Testing multispecies responses in multifactorial ecological experiments. Ecological Monographs 69, 1-24. doi:10.1890/00129615(1999)069[0001:DBRATM]2.0.CO;2

Lenoir, L., Bengtsson, J., Persson, T., 2003a. Effects of conifer resin on soil fauna in potential wood-ant nest materials at different moisture levels. Pedobiologia 47, 19-25. doi:10.1078/0031-4056-00165

Lenoir, L., Bengtsson, J., Persson, T., 2003b. Effects of Formica ants on soil fauna-results from a short-term exclusion and a long-term natural experiment. Oecologia 134, 423-430. doi:10.1007/s00442-002-1143-x

Lenoir, L., Persson, T., Bengtsson, J., 2001. Wood ant nests as potential hot spots for carbon and nitrogen mineralisation. Biology and Fertility of Soils 34, 235-240. doi:10.1007/s003740100405

Lin, R., Qin, F., Shen, B., Shi, Q., Liu, C., Zhang, X., Jiao, Y., Lu, J., Gao, Y., Suarez-Fernandez, M., Lopez-Moya, F., Lopez-Llorca, L.V., Wang, G., Mao, Z., Ling, J., Yang, Y., Cheng, X., Xie, B., 2018. Genome and secretome analysis of Pochonia chlamydosporia provide new insight into egg-parasitic mechanisms. Scientific Reports 8, 1123. doi:10.1038/s41598-018-19169-5

Lindström, S., Rowe, O., Timonen, S., Sundström, L., Johansson, H., 2018. Trends in bacterial and fungal communities in ant nests observed with Terminal-Restriction Fragment Length Polymorphism (T-RFLP) and Next Generation Sequencing (NGS) techniques_-validity and compatibility in ecological studies. PeerJ 6, e5289. doi: $10.7717 /$ peerj.5289

Littlewood, N.A., Young, M.R., 2008. A habitat suitability model for the narrow-headed ant, Formica exsecta, evaluated against independent data. Insect Conservation and Diversity 1, 108-113. doi:10.1111/j.17524598.2008.00014.x

Lladó, S., López-Mondéjar, R., Baldrian, P., 2018. Drivers of microbial community structure in forest soils. Applied Microbiology and Biotechnology 4331-4338. doi:10.1007/s00253-018-8950-4

Lucas, J., Bill, B., Stevenson, B., Kaspari, M., 2017. The microbiome of the ant-built home: the microbial communities of a tropical arboreal ant and its nest. Ecosphere 8, e01639. doi:10.1002/ecs2.1639

Männistö, M., Vuosku, J., Stark, S., Saravesi, K., Suokas, M., Markkola, A., Martz, F., Rautio, P., 2018. Bacterial and fungal communities in boreal forest soil are insensitive to changes in snow cover conditions. FEMS Microbiology Ecology 94, 1-14. doi:10.1093/femsec/fiy123

Marzorati, M., Wittebolle, L., Boon, N., Daffonchio, D., Verstraete, W., 2008a. How to get more out of molecular fingerprints: Practical tools for microbial ecology. Environmental Microbiology 10, 1571-1581. doi:10.1111/j.1462-2920.2008.01572.x

Nkem, J.N., Lobry de Bruyn, L. A., Grant, C.D., Hulugalle, N.R., 2000. The impact of ant bioturbation and foraging activities on surrounding soil properties. Pedobiologia 44, 609-621. doi:Doi 10.1078/S0031-4056(04)70075-X 
Oksanen, J., Blanchet, F., Kindt, R., Legendre, P., Minchin, P., Al., E., 2011. Vegan: Community Ecology Package. R package version 2.0-1.

Pamilo, P., 1991. Life span of queens in the ant Formica exsecta. Insectes Sociaux 38, 111-119. doi: 10.1007/BF01240961

Pimm, S.L., 1984. The complexity and stability of ecosystems. Nature 307, 321-326. doi:10.1038/307321a0

Pirttila, A.M., Laukkanen, H., Pospiech, H., Myllyla, R., Hohtola, A., 2000. Detection of intracellular bacteria in the buds of Scotch pine (Pinus sylvestris L.) by in situ hybridization. Appl.Environ.Microbiol. 66, 3073-3077.

Quast, C., Pruesse, E., Yilmaz, P., Gerken, J., Schweer, T., Yarza, P., Peplies, J., Glöckner, F.O., 2013. The SILVA ribosomal RNA gene database project: improved data processing and web-based tools. Nucleic Acids Research 41, 590-6. doi:10.1093/nar/gks1219

Rodrigues, A., Pagnocca, F.C., Bueno, O.C., Pfenning, L.H., Bacci, M., 2005. Assessment of Microfungi in Fungus Gardens Free of the Leaf-Cutting Ant Atta sexdens rubropilosa (Hymenoptera:Formicidae) . Sociobiology 46, 329-334.

Rosell, F., Collen, P., Parker, H., Bozser, O., 2005. Ecological impact of beavers Castor fiber and \Castor canadensis and their ability to modify ecosystems. Mammal Review 35, 248-276. doi:10.1111/j.1365-2907.2005.00067.x

Rosengren, R., Fortelius, W., Lindström, K., Luther, A., 1987. Phenology and causation of nest heating and thermoregulation in red wood ants of the Formica rufa group studied in coniferous forest habitats in southern Finland. Annales Zoologici Fennici 24, 147-155.

Santalahti, M., Sun, H., Jumpponen, A., Pennanen, T., Heinonsalo, J., 2016. Vertical and seasonal dynamics of fungal communities in boreal Scots pine forest soil of fungi in boreal forests. FEMS Microbiology Ecology 92, 1-31. doi:10.1093/femsec/fiw170

Sen, R., Ishak, H.D., Estrada, D., Dowd, S.E., Hong, E., Mueller, U.G., 2009. Generalized antifungal activity and 454screening of Pseudonocardia and Amycolatopsis bacteria in nests of fungus-growing ants. Proceedings of the National Academy of Sciences 106, 17805-17810. doi:10.1073/pnas.0904827106

Shade, A., Handelsman, J., 2012. Beyond the Venn diagram: The hunt for a core microbiome. Environmental Microbiology 14, 4-12. doi:10.1111/j.1462-2920.2011.02585.x

Shade, A., Peter, H., Allison, S.D., Baho, D.L., Berga, M., Bürgmann, H., Huber, D.H., Langenheder, S., Lennon, J.T., Martiny, J.B.H., Matulich, K.L., Schmidt, T.M., Handelsman, J., 2012. Fundamentals of microbial community resistance and resilience. Frontiers in Microbiology 3, 1-19. doi:10.3389/fmicb.2012.00417

Shannon, P., Markiel, A., Ozier, O., Baliga, N.S., Wang, J.T., Ramage, D., Amin, N., Schwikowski, B., Ideker, T., Ideker, T., 2003. Cytoscape: a software environment for integrated models of biomolecular interaction networks. Genome Research 13, 2498-504. doi:10.1101/gr.1239303

Sietiö, O.M., Tuomivirta, T., Santalahti, M., Kiheri, H., Timonen, S., Sun, H., Fritze, H., Heinonsalo, J., 2018. Ericoid plant species and Pinus sylvestris shape fungal communities in their roots and surrounding soil. New Phytologist 218, 738-751. doi:10.1111/nph.15040

Sorvari, J., Elo, R.A., Härkönen, S.K., 2016. Forest-built nest mounds of red wood ant Formica aquilonia are no good in clear fells. Applied Soil Ecology 101, 101-106. doi:10.1016/j.apsoil.2016.01.019

Sundström, L., Chapuisat, M., Keller, L., 1996. Conditional Manipulation of Sex Ratios by Ant Workers: A Test of Kin Selection Theory. Science 274, 993-995. doi:10.1126/science.274.5289.993

Timonen, S., Sinkko, H., Sun, H., Sietiö, O.M., Rinta-Kanto, J.M., Kiheri, H., Heinonsalo, J., 2017. Ericoid Roots and Mycospheres Govern Plant-Specific Bacterial Communities in Boreal Forest Humus. Microbial Ecology 73, 939953. doi:10.1007/s00248-016-0922-6

Van Borm, S., Buschinger, A., Boomsma, J.J., Billen, J., 2002. Tetraponera ants have gut symbionts related to nitrogenfixing root-nodule bacteria. Proceedings of the Royal Society B-Biological Sciences 2023-2027. doi:10.1098/rspb.2002.2101

Vander Meer, R., 2012. Ant Interactions with Soil Organisms and Associated Semiochemicals. Journal of Chemical Ecology 38, 728-745. doi:10.1007/s10886-012-0140-8 
Vega, F.E., Meyling, N. V., Luangsa-Ard, J.J., Blackwell, M., 2012. Fungal entomopathogens, Second Edi. ed, Insect Pathology. Elsevier Inc. doi:10.1016/B978-0-12-384984-7.00006-3

Vitikainen, E., Haag-Liautard, C., Sundström, L., 2011. Inbreeding and reproductive investment in the ant Formica exsecta. Evolution 65, 2026-2037. doi:10.1111/j.1558-5646.2011.01273.x

Voř́šková, J., Baldrian, P., 2013. Fungal community on decomposing leaf litter undergoes rapid successional changes. The ISME Journal 7, 477-86. doi:10.1038/ismej.2012.116

Wade, J.R., Marchesi, J.R., Sato, T., Weightman, A.J., Martin, T.A., Fry, J.C., Hiom, S.J., Dymock, D., Wade, W.G., 1998. Design and evaluation of useful bacterium-specific PCR primers that amplify genes coding for bacterial 16S rRNA. Applied and Environmental Microbiology 64, 795-799.

Weisburg, W.G., Barns, S.M., Pelletier, D.A., Lane, D.J., 1991. 16S ribosomal DNA amplification for phylogenetic study. Journal of Bacteriology 173, 697-703. doi:10.1128/JB.173.2.697-703.1991

White, T.J., Bruns, T., Lee, S., Taylor, J., 1990. PCR protocols: a guide to methods and application. Academic Press., San Dego.

Wittebolle, L., Marzorati, M., Clement, L., Balloi, A., Daffonchio, D., De Vos, P., Heylen, K., Verstraete, W., Boon, N., 2009. Initial community evenness favours functionality under selective stress. Nature 458, 623-6. doi: $10.1038 /$ nature 07840

Woolfolk, S., Stokes, C.E., Watson, C., Brown, R., 2016. Bacteria Associated with Red Imported Fire Ants (Solenopsis invicta) from Mounds in Mississippi. Southeastern Naturalist 15, 83-101. doi:10.1656/058.015.0107

Young, J.P.W., 2012. A molecular guide to the taxonomy of arbuscular mycorrhizal fungi. New Phytologist 193, 823826. doi:10.1111/j.1469-8137.2011.04029.x

Žifčáková, L., Větrovský, T., Lombard, V., Henrissat, B., Howe, A., Baldrian, P., 2017. Feed in summer, rest in winter: microbial carbon utilization in forest topsoil. Microbiome 5, 122. doi:10.1186/s40168-017-0340-0 


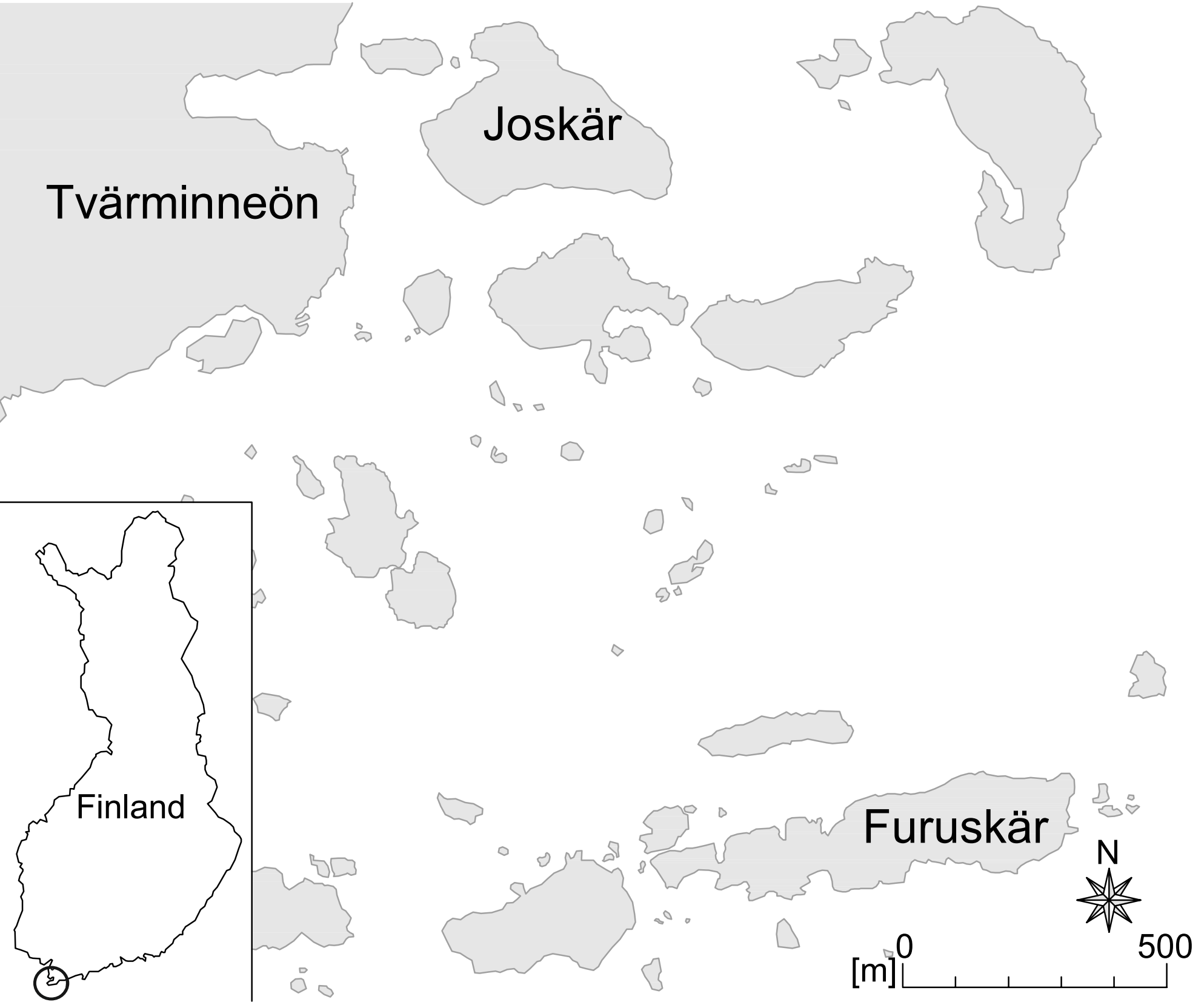

Figure S1. The sampling area showing the two islands in Tvärminne archipelago. 
Table S1. Read counts from the UPARSE pipeline.

\begin{tabular}{lrr}
\hline & BACTERIA & \multicolumn{1}{c}{ FUNGI } \\
\hline Total reads (R1+R2) & 9224540 & 6147738 \\
Merged reads & 2928489 & 3021162 \\
Filtered reads & 2166255 & 2250044 \\
Reads in OTU table & 2404410 & 894635 \\
Reads (singletons and doubletons removed) & 2404324 & 894469 \\
Mean no. of reads / sample (S.D.) & $66787(17235)$ & $24846(10447)$ \\
Lowest no. of reads / sample & 31931 & 7141
\end{tabular}

Table S2. Network descriptors for the monthly networks.

\begin{tabular}{lrrr}
\hline BACTERIA & May & June & August \\
\hline Number of nodes in total network & 2475 & 2173 & 2367 \\
Number of subnetworks & 1 & 2 & 1 \\
Number of nodes in largest subnetwork & 2475 & 2171 & 2367 \\
Clustering coefficient & 0.777 & 0.747 & 0.736 \\
Network centrality & 0.130 & 0.120 & 0.083 \\
Network density & 0.084 & 0.062 & 0.061 \\
Network heterogeneity & 0.713 & 0.761 & 0.599
\end{tabular}

\section{FUNGI}

Number of nodes in total network

May June August

Number of subnetworks

$\begin{array}{rrr}714 & 711 & 779 \\ 1 & 1 & 1 \\ 714 & 711 & 779 \\ 0.850 & 0.806 & 0.851 \\ 0.128 & 0.104 & 0.098 \\ 0.086 & 0.069 & 0.072 \\ 0.760 & 0.643 & 0.599\end{array}$

Number of nodes in largest subnetwork

Clustering coefficient 
Table S3. Comparison of bacterial read abundance in nest and reference soils, at the level of genera, presented as the percentage of TA across both environments. Only genera, which are significantly $(\mathrm{p} \leq 0.05)$ more abundant in either environment, are shown. $(D F=1, D F D e n=29$.

\begin{tabular}{|c|c|c|c|c|c|c|c|c|}
\hline \multirow[t]{2}{*}{ Genus } & \multirow[t]{2}{*}{$\boldsymbol{F}$} & \multirow[t]{2}{*}{$p$} & \multicolumn{3}{|l|}{ Nest } & \multicolumn{3}{|c|}{ Reference soils } \\
\hline & & & reads & $\%$ of TA & $\begin{array}{l}\text { Core } \\
\text { indicator }\end{array}$ & reads & $\begin{array}{r}\% \text { of } \\
\text { TA }\end{array}$ & $\begin{array}{l}\text { Core } \\
\text { indicator }\end{array}$ \\
\hline Acidaminococcus & 4.52 & 0.042 & 12 & 0.001 & & 0 & 0 & \\
\hline Acidisoma & 11.4 & 0.002 & 3565 & 0.31 & & 1661 & 0.14 & \\
\hline Acidisphaera & 35.86 & 0.001 & 51 & 0.004 & & 663 & 0.06 & yes \\
\hline Aciditerrimonas & 14.57 & 0.001 & 1621 & 0.14 & & 3968 & 0.35 & \\
\hline Acidobacteria Gp1 & 8.68 & 0.006 & 30067 & 2.62 & yes & 56842 & 4.94 & yes \\
\hline Acidobacteria Gp13 & 8.26 & 0.008 & 12 & 0.001 & & 197 & 0.02 & \\
\hline Acidobacteria Gp2 & 11.69 & 0.002 & 627 & 0.05 & & 10002 & 0.87 & yes \\
\hline Acidobacteria Gp3 & 14.11 & 0.001 & 2848 & 0.25 & & 5837 & 0.51 & yes \\
\hline Acidobacteria Gp5 & 5.16 & 0.031 & 10 & 0.001 & & 452 & 0.04 & yes \\
\hline Acidobacteria Gp6 & 4.41 & 0.045 & 206 & 0.02 & & 2148 & 0.19 & \\
\hline Acidobacteria Gp7 & 9.49 & 0.005 & 30 & 0.003 & & 598 & 0.05 & \\
\hline Acidocella & 4.26 & 0.048 & 5133 & 0.45 & & 2917 & 0.25 & \\
\hline Actinocatenispora & 4.58 & 0.041 & 126 & 0.01 & & 2 & 0.0002 & \\
\hline Actinomycetospora & 25.78 & 0.001 & 1143 & 0.1 & yes & 23 & 0.002 & \\
\hline Actinospica & 5.92 & 0.021 & 274 & 0.02 & & 1131 & 0.1 & \\
\hline Armatimonadetes_gp1 & 7.51 & 0.01 & 5354 & 0.47 & & 3060 & 0.27 & \\
\hline Armatimonadetes_gp3 & 13.41 & 0.001 & 576 & 0.05 & & 1322 & 0.12 & \\
\hline Armatimonadetes_gp4 & 5.7 & 0.024 & 27 & 0.002 & & 95 & 0.01 & \\
\hline Armatimonadetes_gp5 & 31.32 & 0.001 & 429 & 0.04 & & 1984 & 0.17 & \\
\hline Asticcacaulis & 4.63 & 0.04 & 154 & 0.01 & & 436 & 0.04 & \\
\hline Beijerinckia & 17.4 & 0.001 & 361 & 0.03 & & 19 & 0.002 & \\
\hline BRC1 I.s & 5.35 & 0.028 & 5 & 0.0004 & & 98 & 0.01 & \\
\hline Brevundimonas & 22.35 & 0.001 & 3460 & 0.3 & yes & 828 & 0.07 & \\
\hline Burkholderia & 12.36 & 0.002 & 24167 & 2.1 & yes & 10459 & 0.91 & \\
\hline Byssovorax & 6.24 & 0.018 & 37 & 0.003 & & 511 & 0.04 & \\
\hline Catenulispora & 7.89 & 0.009 & 26 & 0.002 & & 209 & 0.02 & \\
\hline Caulobacter & 8.25 & 0.008 & 10261 & 0.89 & & 13528 & 1.18 & \\
\hline Chitinophaga & 4.66 & 0.039 & 73 & 0.01 & & 340 & 0.03 & \\
\hline Chlorophyta & 7.42 & 0.011 & 825 & 0.07 & & 120 & 0.01 & \\
\hline Collimonas & 5.91 & 0.022 & 6 & 0.001 & & 305 & 0.03 & \\
\hline Conexibacter & 7.84 & 0.009 & 1705 & 0.15 & & 901 & 0.08 & \\
\hline Cryptosporangium & 4.44 & 0.044 & 181 & 0.02 & & 19 & 0.002 & \\
\hline Curvibacter & 13.56 & 0.001 & 2 & 0.0002 & & 101 & 0.01 & \\
\hline Demequina & 4.92 & 0.035 & 19 & 0.002 & & 242 & 0.02 & \\
\hline Dokdonella & 6.01 & 0.021 & 105 & 0.01 & & 2008 & 0.17 & \\
\hline Ferruginibacter & 5.87 & 0.022 & 839 & 0.07 & & 2056 & 0.18 & yes \\
\hline Frondihabitans & 12.24 & 0.002 & 796 & 0.07 & yes & 48 & 0.004 & \\
\hline Gemmata & 11.52 & 0.002 & 56 & 0.005 & & 245 & 0.02 & \\
\hline Gemmatimonas & 8.31 & 0.007 & 1819 & 0.16 & & 4004 & 0.35 & \\
\hline Gordonia & 10.03 & 0.004 & 22 & 0.002 & & 0 & 0 & \\
\hline Herbiconiux & 5.74 & 0.023 & 3196 & 0.28 & & 1781 & 0.15 & \\
\hline
\end{tabular}




\begin{tabular}{|c|c|c|c|c|c|c|c|}
\hline Ideonella & 7.35 & 0.011 & 105 & 0.01 & & 519 & 0.05 \\
\hline Kineococcus & 5.05 & 0.032 & 50 & 0.004 & & 1 & 0.0001 \\
\hline Kofleria & 17.79 & 0.001 & 62 & 0.01 & & 1402 & 0.12 \\
\hline Labrys & 5 & 0.033 & 160 & 0.01 & & 314 & 0.03 \\
\hline Marmoricola & 5.79 & 0.023 & 5208 & 0.45 & & 1086 & 0.09 \\
\hline Massilia & 5.6 & 0.025 & 7787 & 0.68 & & 1678 & 0.15 \\
\hline Methylobacterium & 14.68 & 0.001 & 3925 & 0.34 & yes & 193 & 0.02 \\
\hline Microlunatus & 4.98 & 0.034 & 361 & 0.03 & & 64 & 0.01 \\
\hline Mycobacterium & 14.89 & 0.001 & 28640 & 2.49 & & 8061 & 0.7 \\
\hline Nevskia & 5.08 & 0.032 & 187 & 0.02 & & 767 & 0.07 \\
\hline Nitrosospira & 4.35 & 0.046 & 141 & 0.01 & & 40 & 0.003 \\
\hline Nocardioides & 4.34 & 0.046 & 3036 & 0.26 & & 1338 & 0.12 \\
\hline Novosphingobium & 5.91 & 0.022 & 2484 & 0.22 & & 1267 & 0.11 \\
\hline Ohtaekwangia & 5.46 & 0.027 & 183 & 0.02 & & 2010 & 0.17 \\
\hline Opitutus & 44.73 & 0.001 & 1157 & 0.1 & & 6338 & 0.55 \\
\hline Pelomonas & 8.18 & 0.008 & 53 & 0.005 & & 529 & 0.05 \\
\hline Phenylobacterium & 6.61 & 0.016 & 3211 & 0.28 & & 5579 & 0.49 \\
\hline Phycisphaera & 26.39 & 0.001 & 5 & 0.0004 & & 414 & 0.04 \\
\hline Planctomyces & 4.71 & 0.038 & 5 & 0.0004 & & 19 & 0.002 \\
\hline Pseudonocardia & 16.82 & 0.001 & 1959 & 0.17 & yes & 637 & 0.06 \\
\hline Rhizomicrobium & 9.41 & 0.005 & 12539 & 1.09 & & 22876 & 1.99 \\
\hline Rhodopila & 6.97 & 0.013 & 697 & 0.06 & & 117 & 0.01 \\
\hline Rudaea & 9.88 & 0.004 & 127 & 0.01 & & 3391 & 0.29 \\
\hline Schlesneria & 11.63 & 0.002 & 15 & 0.001 & & 279 & 0.02 \\
\hline Sorangium & 29.02 & 0.001 & 145 & 0.01 & & 743 & 0.06 \\
\hline Spirochaeta & 5.29 & 0.029 & 0 & 0 & & 190 & 0.02 \\
\hline Sporichthya & 6.66 & 0.015 & 101 & 0.01 & & 415 & 0.04 \\
\hline Stella & 12.36 & 0.002 & 38 & 0.003 & & 8 & 0.001 \\
\hline Steroidobacter & 15.07 & 0.001 & 250 & 0.02 & & 1324 & 0.12 \\
\hline Streptophyta & 8.12 & 0.008 & 4600 & 0.4 & & 382 & 0.03 \\
\hline Terriglobus & 14.32 & 0.001 & 1540 & 0.13 & & 234 & 0.02 \\
\hline $\begin{array}{l}\text { Variovorax } \\
\text { Verrucomicrob. }\end{array}$ & 7.57 & 0.01 & 985 & 0.09 & & 2603 & 0.23 \\
\hline Subdiv3 & 16.3 & 0.001 & 2 & 0.0002 & & 25 & 0.002 \\
\hline Zavarzinella & 41.03 & 0.001 & 7 & 0.001 & & 176 & 0.02 \\
\hline Not identified & 0.95 & 0.338 & 275260 & 23.95 & & 285242 & 24.81 \\
\hline
\end{tabular}


Table S5. Comparison of fungal read abundance in nest and reference soils, at the level of genera, presented as the percentage of TA across both environments. Only genera, which are significantly $(\mathrm{p} \leq 0.05)$ more abundant in either environment, are shown. $(D F=1, D F D e n=29$. $)$

\begin{tabular}{|c|c|c|c|c|c|c|c|c|}
\hline Genus & $\boldsymbol{F}$ & $p$ & $\begin{array}{l}\text { Nest } \\
\text { reads } \\
\end{array}$ & $\%$ of TA & $\begin{array}{l}\text { Core } \\
\text { indicator }\end{array}$ & reads & $\begin{array}{l}\text { ce soils } \\
\% \text { of TA }\end{array}$ & $\begin{array}{l}\text { Core } \\
\text { indicator }\end{array}$ \\
\hline Bionectria & 5.99 & 0.021 & 0 & 0 & & 37 & 0.01 & \\
\hline Calycina & 7.28 & 0.012 & 3 & 0.001 & & 206 & 0.08 & yes \\
\hline Ceratobasidium & 4.63 & 0.04 & 7 & 0.003 & & 29 & 0.01 & \\
\hline Chaunopycnis & 4.28 & 0.048 & 8 & 0.003 & & 41 & 0.02 & \\
\hline Cladophialophora & 14.09 & 0.001 & 5016 & 1.95 & & 1186 & 0.46 & \\
\hline Cryptodiscus & 5.7 & 0.024 & 245 & 0.1 & & 1 & 0.0004 & \\
\hline Exobasidium & 4.64 & 0.04 & 113 & 0.04 & & 50 & 0.02 & \\
\hline Exophiala & 7.08 & 0.013 & 350 & 0.14 & yes & 92 & 0.04 & \\
\hline Fellomyces & 4.44 & 0.044 & 15 & 0.01 & & 1 & 0.0004 & \\
\hline Galerina & 4.75 & 0.038 & 2 & 0.001 & & 76 & 0.03 & \\
\hline Gliomastix & 5.64 & 0.024 & 2 & 0.001 & & 15 & 0.01 & \\
\hline Hyaloscypha & 22.51 & 0.001 & 1023 & 0.4 & & 37 & 0.01 & \\
\hline Hymenoscyphus & 4.35 & 0.046 & 0 & 0 & & 12 & 0.005 & \\
\hline Hyphodiscus & 5.5 & 0.026 & 64 & 0.02 & & 598 & 0.23 & \\
\hline Infundichalara & 5.38 & 0.028 & 61 & 0.02 & & 4 & 0.002 & \\
\hline Inocybe & 4.39 & 0.045 & 0 & 0 & & 43 & 0.02 & \\
\hline Lactarius & 5.35 & 0.028 & 1 & 0.0004 & & 677 & 0.26 & \\
\hline Lecanicillium & 7.18 & 0.012 & 1 & 0.0004 & & 81 & 0.03 & \\
\hline Meliniomyces & 14.55 & 0.001 & 215 & 0.08 & & 1697 & 0.66 & \\
\hline Mollisia & 5.21 & 0.03 & 89 & 0.03 & & 399 & 0.16 & \\
\hline Mortierella & 12.61 & 0.001 & 3 & 0.001 & & 332 & 0.13 & yes \\
\hline Mycena & 6.61 & 0.016 & 54 & 0.02 & & 246 & 0.1 & \\
\hline Neonectria & 12.26 & 0.002 & 12 & 0.005 & & 241 & 0.09 & \\
\hline Oidiodendron & 9.59 & 0.004 & 15303 & 5.95 & yes & 1990 & 0.77 & \\
\hline Penicillium & 10.96 & 0.003 & 1006 & 0.39 & & 140 & 0.05 & \\
\hline Phialocephala & 30.71 & 0.001 & 153 & 0.06 & & 1604 & 0.62 & \\
\hline Piloderma & 7.5 & 0.01 & 0 & 0 & & 1818 & 0.71 & \\
\hline Pochonia & 16.92 & 0.001 & 18 & 0.01 & & 242 & 0.09 & yes \\
\hline Rhizoscyphus & 6.39 & 0.017 & 1067 & 0.42 & & 372 & 0.14 & \\
\hline Rhodosporidium & 16.03 & 0.001 & 19 & 0.01 & & 0 & 0 & \\
\hline Russula & 5.04 & 0.033 & 0 & 0 & & 87 & 0.03 & \\
\hline Scleroconidioma & 20.47 & 0.001 & 349 & 0.14 & yes & 1 & 0.0004 & \\
\hline Suillus & 5.85 & 0.022 & 3 & 0.001 & & 183 & 0.07 & \\
\hline Thelebolus & 5.15 & 0.031 & 10222 & 3.98 & & 112 & 0.04 & \\
\hline Tomentella & 7.61 & 0.01 & 0 & 0 & & 73 & 0.03 & \\
\hline Umbelopsis & 5.59 & 0.025 & 388 & 0.15 & yes & 45 & 0.02 & \\
\hline Verticillium & 8.49 & 0.007 & 7 & 0.003 & & 104 & 0.04 & \\
\hline Xenochalara & 4.54 & 0.042 & 706 & 0.27 & & 225 & 0.09 & \\
\hline Not identified & 15.19 & 0.001 & 66184 & 25.74 & & 85602 & 33.3 & \\
\hline
\end{tabular}




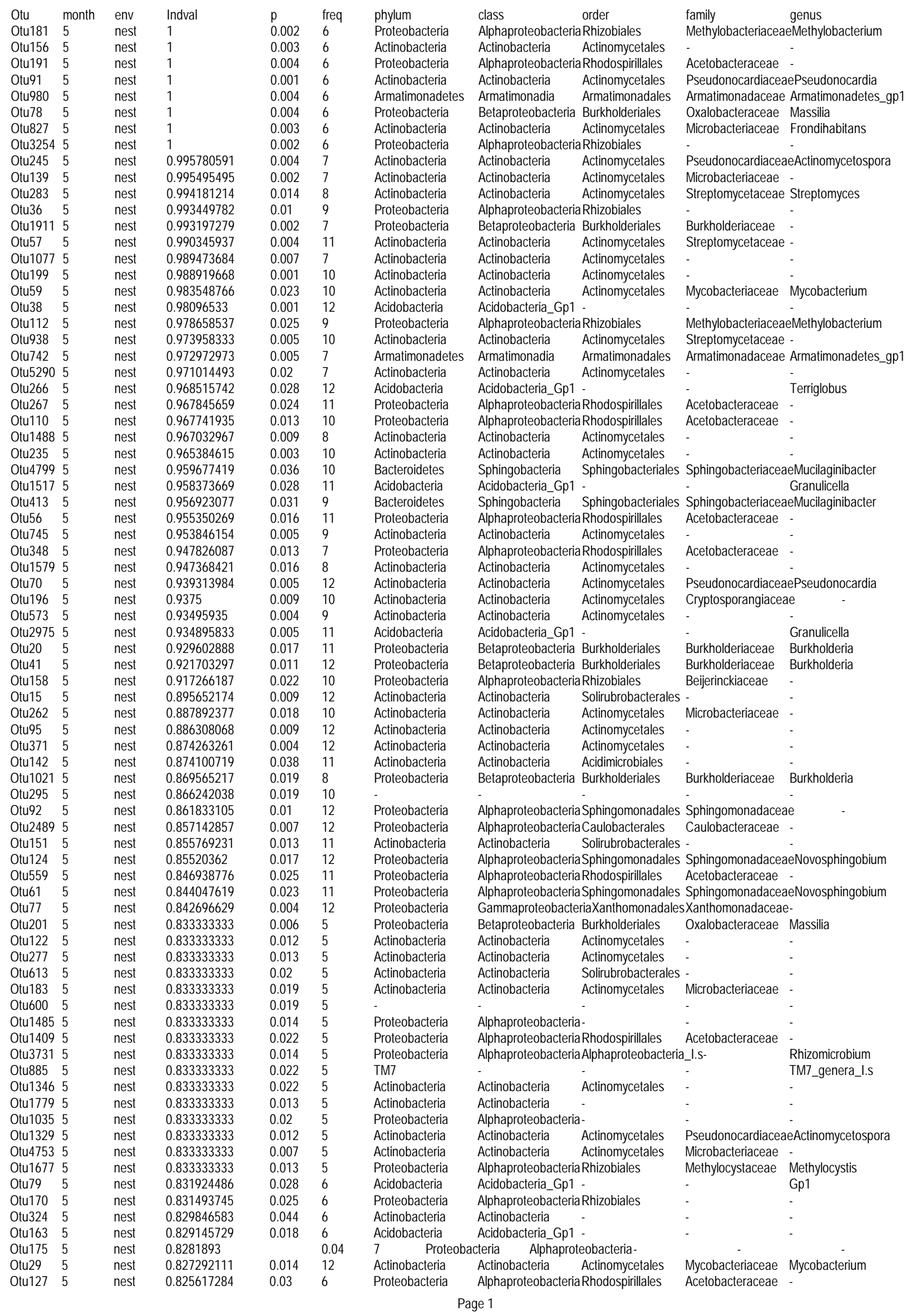




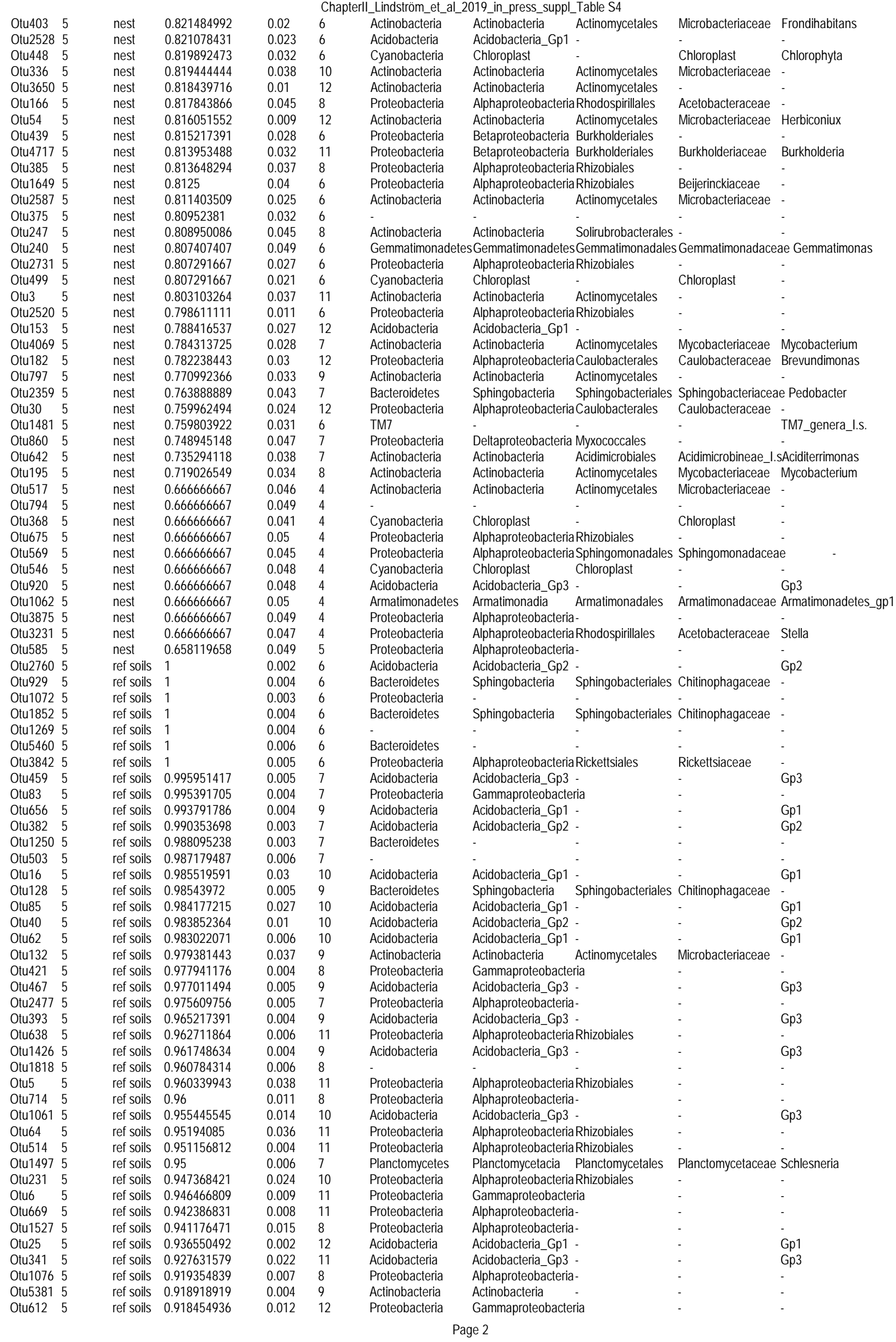




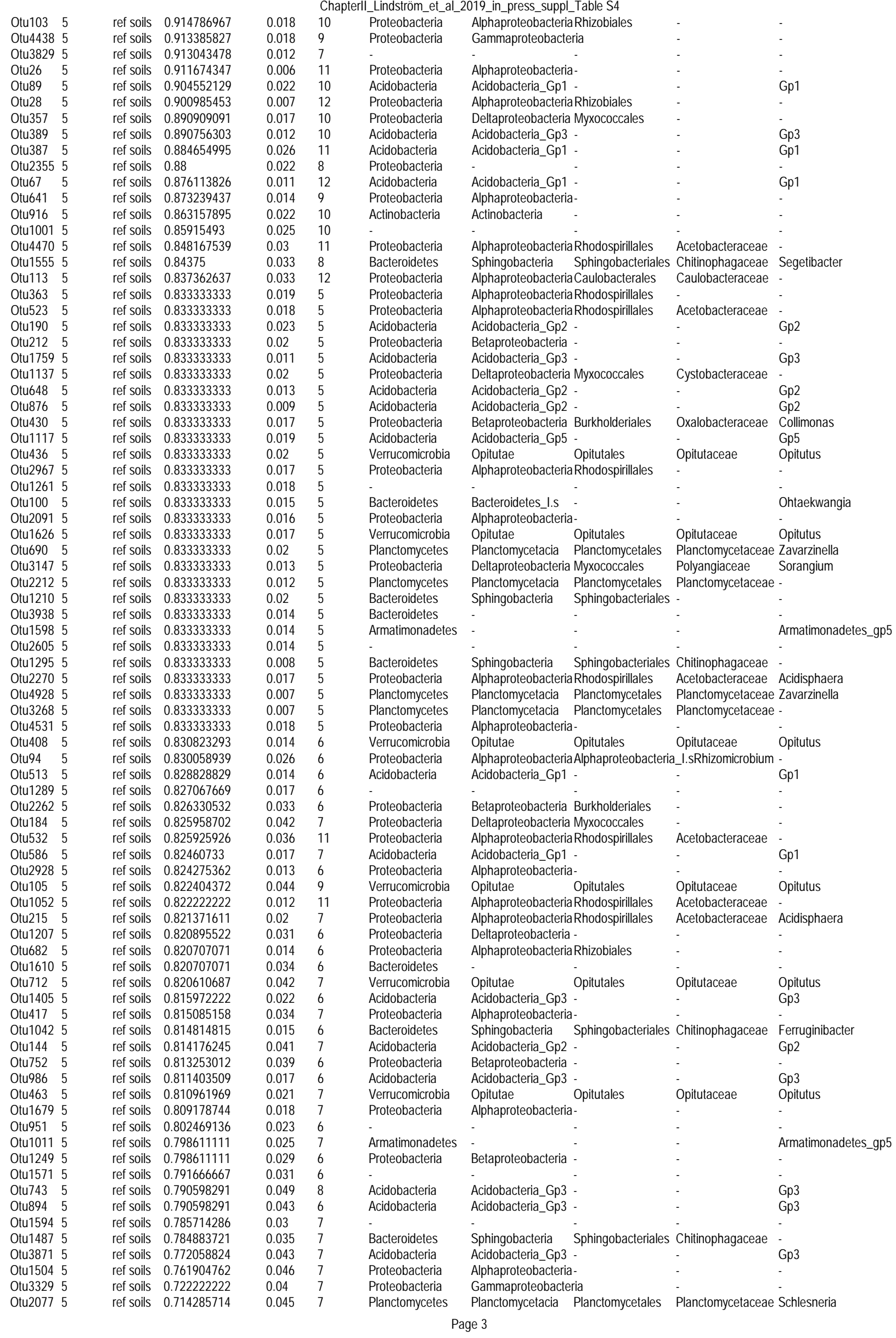




\begin{tabular}{|c|c|c|c|c|c|c|c|c|c|c|}
\hline & & & & & & & & & & \\
\hline Otu65 & 5 & ref soils & 0.701760325 & 0.049 & 12 & Proteobacteria & Alphaproteobacteria & aCaulobacterales & Caulobacteraceae & Caulobacter \\
\hline Otu1469 & 5 & ref soils & 0.666666667 & 0.05 & 4 & Acidobacteria & Acidobacteria_Gp6 & - & - & Gp6 \\
\hline Otu819 & 5 & ref soils & 0.666666667 & 0.043 & 4 & Acidobacteria & Acidobacteria_Gp3 & - & - & Gp3 \\
\hline Otu1017 & 5 & ref soils & 0.642857143 & 0.047 & 5 & Acidobacteria & Acidobacteria_Gp1 & - & - & Gp1 \\
\hline Otu183 & 6 & nest & 1 & 0.004 & 6 & Actinobacteria & Actinobacteria & Actinomycetales & Microbacteriaceae & - \\
\hline Otu122 & 6 & nest & 1 & 0.003 & 6 & Actinobacteria & Actinobacteria & Actinomycetales & - & - \\
\hline Otu1409 & 6 & nest & 1 & 0.003 & 6 & Proteobacteria & Alphaproteobacteria & aRhodospirillales & Acetobacteraceae & - \\
\hline Otu368 & 6 & nest & 1 & 0.002 & 6 & Cyanobacteria & Chloroplast & - & Chloroplast & - \\
\hline Otu827 & 6 & nest & 1 & 0.005 & 6 & Actinobacteria & Actinobacteria & Actinomycetales & Microbacteriaceae & Frondihabitans \\
\hline Otu79 & 6 & nest & 0.996261682 & 0.011 & 10 & Acidobacteria & Acidobacteria_Gp1 & - & - & Gp1 \\
\hline Otu156 & 6 & nest & 0.990196078 & 0.002 & 8 & Actinobacteria & Actinobacteria & Actinomycetales & - & - \\
\hline Otu322 & 6 & nest & 0.990196078 & 0.006 & 7 & Proteobacteria & Alphaproteobacteria & aRhizobiales & - & - \\
\hline Otu794 & 6 & nest & 0.987341772 & 0.003 & 7 & - & - & - & - & - \\
\hline Otu490 & 6 & nest & 0.976470588 & 0.009 & 8 & Proteobacteria & Alphaproteobacteria & aRhodospirillales & Acetobacteraceae & - \\
\hline Otu191 & 6 & nest & 0.975409836 & 0.004 & 7 & Proteobacteria & Alphaproteobacteria & aRhodospirillales & Acetobacteraceae & - \\
\hline Otu36 & 6 & nest & 0.974358974 & 0.004 & 9 & Proteobacteria & Alphaproteobacteria & aRhizobiales & - & - \\
\hline Otu385 & 6 & nest & 0.97080292 & 0.001 & 9 & Proteobacteria & Alphaproteobacteria & aRhizobiales & - & - \\
\hline Otu245 & 6 & nest & 0.964444444 & 0.008 & 8 & Actinobacteria & Actinobacteria & Actinomycetales & Pseudonocardiacea & ae Actinomycetospora \\
\hline Otu143 & 6 & nest & 0.964401294 & 0.035 & 10 & Proteobacteria & Alphaproteobacteria & aRhodospirillales & Acetobacteraceae & - \\
\hline Otu335 & 6 & nest & 0.96097561 & 0.002 & 8 & Proteobacteria & Betaproteobacteria & Burkholderiales & Oxalobacteraceae & Massilia \\
\hline Otu1531 & 6 & nest & 0.957894737 & 0.01 & 8 & Acidobacteria & Acidobacteria_Gp1 & - & - & Granulicella \\
\hline Otu109 & 6 & nest & 0.956175299 & 0.01 & 9 & Proteobacteria & Alphaproteobacteria & aRhizobiales & Beijerinckiaceae & - \\
\hline Otu338 & 6 & nest & 0.95505618 & 0.022 & 9 & Actinobacteria & Actinobacteria & Actinomycetales & - & - \\
\hline Otu139 & 6 & nest & 0.953571429 & 0.015 & 8 & Actinobacteria & Actinobacteria & Actinomycetales & Microbacteriaceae & - \\
\hline Otu247 & 6 & nest & 0.952380952 & 0.008 & 11 & Actinobacteria & Actinobacteria & Solirubrobacterales & - & - \\
\hline Otu675 & 6 & nest & 0.952380952 & 0.003 & 7 & Proteobacteria & Alphaproteobacteria & aRhizobiales & - & - \\
\hline Otu166 & 6 & nest & 0.94966443 & 0.026 & 10 & Proteobacteria & Alphaproteobacteria & aRhodospirillales & Acetobacteraceae & - \\
\hline Otu112 & 6 & nest & 0.949333333 & 0.027 & 9 & Proteobacteria & Alphaproteobacteria & aRhizobiales & Methylobacteriacea & eMethylobacterium \\
\hline Otu739 & 6 & nest & 0.946236559 & 0.007 & 9 & Acidobacteria & Acidobacteria_Gp1 & - & - & - \\
\hline Otu147 & 6 & nest & 0.944903581 & 0.029 & 10 & Cyanobacteria & Chloroplast & - & Chloroplast & Streptophyta \\
\hline Otu403 & 6 & nest & 0.944444444 & 0.018 & 9 & Actinobacteria & Actinobacteria & Actinomycetales & Microbacteriaceae & Frondihabitans \\
\hline Otu24 & 6 & nest & 0.940414508 & 0.024 & 10 & Actinobacteria & Actinobacteria & Actinomycetales & Mycobacteriaceae & Mycobacterium \\
\hline Otu303 & 6 & nest & 0.93989071 & 0.009 & 7 & - & - & - & - & - \\
\hline Otu20 & 6 & nest & 0.938695652 & 0.002 & 12 & Proteobacteria & Betaproteobacteria & Burkholderiales & Burkholderiaceae & Burkholderia \\
\hline Otu324 & 6 & nest & 0.9375 & 0.01 & 8 & Actinobacteria & Actinobacteria & - & - & - \\
\hline Otu4103 & 6 & nest & 0.931623932 & 0.023 & 10 & Acidobacteria & Acidobacteria_Gp3 & - & - & Gp3 \\
\hline Otu938 & 6 & nest & 0.931174089 & 0.009 & 9 & Actinobacteria & Actinobacteria & Actinomycetales & Streptomycetaceae & - \\
\hline Otu57 & 6 & nest & 0.923371648 & 0.006 & 8 & Actinobacteria & Actinobacteria & Actinomycetales & Streptomycetaceae & - \\
\hline Otu5447 & 6 & nest & 0.923076923 & 0.013 & 7 & Actinobacteria & Actinobacteria & Solirubrobacterales & - & - \\
\hline Otu38 & 6 & nest & 0.921503958 & 0.017 & 12 & Acidobacteria & Acidobacteria_Gp1 & - & - & - \\
\hline Otu545 & 6 & nest & 0.921052632 & 0.01 & 7 & Proteobacteria & Alphaproteobacteria & aRhizobiales & - & - \\
\hline Otu745 & 6 & nest & 0.912280702 & 0.008 & 10 & Actinobacteria & Actinobacteria & Actinomycetales & - & - \\
\hline Otu980 & 6 & nest & 0.911392405 & 0.02 & 10 & Armatimonadetes & Armatimonadia & Armatimonadales & Armatimonadaceae & Armatimonadetes_gp1 \\
\hline Otu110 & 6 & nest & 0.908227848 & 0.006 & 11 & Proteobacteria & Alphaproteobacteria & aRhodospirillales & Acetobacteraceae & - \\
\hline Otu235 & 6 & nest & 0.899543379 & 0.004 & 10 & Actinobacteria & Actinobacteria & Actinomycetales & - & - \\
\hline Otu267 & 6 & nest & 0.898734177 & 0.022 & 10 & Proteobacteria & Alphaproteobacteria & aRhodospirillales & Acetobacteraceae & - \\
\hline Otu1492 & 6 & nest & 0.894736842 & 0.008 & 8 & Proteobacteria & Betaproteobacteria & Burkholderiales & Burkholderiaceae & Burkholderia \\
\hline Otu4717 & 6 & nest & 0.884615385 & 0.009 & 9 & Proteobacteria & Betaproteobacteria & Burkholderiales & Burkholderiaceae & Burkholderia \\
\hline Otu41 & 6 & nest & 0.872655479 & 0.026 & 12 & Proteobacteria & Betaproteobacteria & Burkholderiales & Burkholderiaceae & Burkholderia \\
\hline Otu181 & 6 & nest & 0.868131868 & 0.014 & 8 & Proteobacteria & Alphaproteobacteria & aRhizobiales & Methylobacteriacea & eMethylobacterium \\
\hline Otu188 & 6 & nest & 0.859756098 & 0.044 & 10 & Bacteroidetes & Sphingobacteria & Sphingobacteriales & Sphingobacteriacea & aeMucilaginibacter \\
\hline Otu3 & 6 & nest & 0.858514961 & 0.014 & 12 & Actinobacteria & Actinobacteria & Actinomycetales & - & - \\
\hline Otu573 & 6 & nest & 0.856060606 & 0.018 & 8 & Actinobacteria & Actinobacteria & Actinomycetales & - & - \\
\hline Otu158 & 6 & nest & 0.855614973 & 0.03 & 11 & Proteobacteria & Alphaproteobacteria & aRhizobiales & Beijerinckiaceae & - \\
\hline Otu666 & 6 & nest & 0.853080569 & 0.041 & 10 & Proteobacteria & Alphaproteobacteria & aCaulobacterales & Caulobacteraceae & Brevundimonas \\
\hline Otu266 & 6 & nest & 0.851963746 & 0.046 & 12 & Acidobacteria & Acidobacteria_Gp1 & - & - & Terriglobus \\
\hline Otu1974 & 6 & nest & 0.836689038 & 0.029 & 12 & Proteobacteria & Betaproteobacteria & Burkholderiales & Burkholderiaceae & Burkholderia \\
\hline Otu456 & 6 & nest & 0.833333333 & 0.032 & 12 & TM7 & - & - & - & TM7_genera_I.s \\
\hline Otu845 & 6 & nest & 0.833333333 & 0.019 & 5 & TM7 & - & - & T & M7_genera_İ.s \\
\hline Otu585 & 6 & nest & 0.833333333 & 0.015 & 5 & Proteobacteria & Alphaproteobacteria & a- & - & 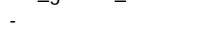 \\
\hline Otu855 & 6 & nest & 0.833333333 & 0.009 & 5 & Acidobacteria & Acidobacteria_Gp3 & - & - & Gp3 \\
\hline Otu3254 & 6 & nest & 0.833333333 & 0.016 & 5 & Proteobacteria & Alphaproteobacteria & aRhizobiales & - & - \\
\hline Otu2055 & 6 & nest & 0.833333333 & 0.012 & 5 & - & - & - & - & - \\
\hline Otu1173 & 6 & nest & 0.833333333 & 0.018 & 5 & Proteobacteria & Deltaproteobacteria & Myxocccales & - & - \\
\hline Otu510 & 6 & nest & 0.833333333 & 0.017 & 5 & Cyanobacteria & Chloroplast & - & Chloroplast & Chlorophyta \\
\hline Otu4126 & 6 & nest & 0.833333333 & 0.013 & 5 & Proteobacteria & Betaproteobacteria & Burkholderiales & - & - \\
\hline Otu517 & 6 & nest & 0.833333333 & 0.017 & 5 & Actinobacteria & Actinobacteria & Actinomycetales & Microbacteriaceae & - \\
\hline Otu23 & 6 & nest & 0.830969267 & 0.026 & 7 & Proteobacteria & Alphaproteobacteria & aRhodospirillales & Acetobacteraceae & - \\
\hline Otu237 & 6 & nest & 0.827338129 & 0.029 & 6 & Proteobacteria & Alphaproteobacteria & aRhodospirillales & Acetobacteraceae & - \\
\hline Otu97 & 6 & nest & 0.823195458 & 0.031 & 6 & Proteobacteria & Alphaproteobacteria & aRhodospirillales & Acetobacteraceae & - \\
\hline Otu600 & 6 & nest & 0.82278481 & 0.016 & 6 & - & - & - & - & - \\
\hline Otu1911 & 6 & nest & 0.821678322 & 0.02 & 7 & Proteobacteria & Betaproteobacteria & Burkholderiales & Burkholderiaceae & - \\
\hline Otu236 & 6 & nest & 0.8203125 & & 0.019 & $6-$ & - & - & - & - \\
\hline Otu1012 & 6 & nest & 0.815602837 & 0.021 & 6 & Acidobacteria & Acidobacteria_Gp3 & - & - & Gp3 \\
\hline Otu867 & 6 & nest & 0.815412186 & 0.037 & 7 & Acidobacteria & Acidobacteria_Gp3 & - & - & Gp3 \\
\hline Otu375 & 6 & nest & 0.814814815 & 0.022 & 7 & - & - & - & - & - \\
\hline Otu604 & 6 & nest & 0.812757202 & 0.017 & 7 & - & - & - & - & - \\
\hline Otu1077 & 6 & nest & 0.810185185 & 0.026 & 6 & Actinobacteria & Actinobacteria & Actinomycetales & - & - \\
\hline Otu91 & 6 & nest & 0.80952381 & 0.04 & 7 & Actinobacteria & Actinobacteria & Actinomycetales & Pseudonocardiacea & aePseudonocardia \\
\hline Otu571 & 6 & nest & 0.808823529 & 0.026 & 7 & Proteobacteria & Alphaproteobacteria & aRhodospirillales & Acetobacteraceae & - \\
\hline Otu3525 & 6 & nest & 0.808695652 & 0.02 & 12 & Proteobacteria & Alphaproteobacteria & aRhodospirillales & Acetobacteraceae & - \\
\hline
\end{tabular}




\begin{tabular}{|c|c|c|c|c|c|c|c|c|c|c|}
\hline \multicolumn{11}{|c|}{ Chapterll_Lindström_et_al_2019_in_press_suppl_Table S4 } \\
\hline Otu175 & 6 & nest & 0.808491418 & 0.032 & 8 & Proteobacteria & Alphaproteobacteria & & - & - \\
\hline Otu1595 & 6 & nest & 0.807291667 & 0.027 & 6 & Proteobacteria & Alphaproteobacteria & aRhizobiales & - & - \\
\hline Otu199 & 6 & nest & 0.806451613 & 0.015 & 11 & Actinobacteria & Actinobacteria & Actinomycetales & - & - \\
\hline Otu120 & 6 & nest & 0.803255485 & 0.049 & 7 & Acidobacteria & Acidobacteria_Gp1 & - & - & - \\
\hline Otu70 & 6 & nest & 0.8 & 0.036 & 12 & Actinobacteria & Actinobacteria & Actinomycetales & Pseudonocardiacea & aePseudonocardia \\
\hline Otu277 & 6 & nest & 0.794270833 & 0.017 & 7 & Actinobacteria & Actinobacteria & Actinomycetales & - & - \\
\hline Otu283 & 6 & nest & 0.781835206 & 0.034 & 6 & Actinobacteria & Actinobacteria & Actinomycetales & Streptomycetaceae & Streptomyces \\
\hline Otu613 & 6 & nest & 0.779569892 & 0.034 & 6 & Actinobacteria & Actinobacteria & Solirubrobacterales & - & - \\
\hline Otu151 & 6 & nest & 0.778026906 & 0.04 & 12 & Actinobacteria & Actinobacteria & Solirubrobacterales & - & - \\
\hline Otu2183 & 6 & nest & 0.75 & 0.032 & 11 & Planctomycetes & Planctomycetacia & Planctomycetales & Planctomycetaceae & Singulisphaera \\
\hline Otu2489 & 6 & nest & 0.744186047 & 0.011 & 12 & Proteobacteria & Alphaproteobacteria & aCaulobacterales & Caulobacteraceae & - \\
\hline Otu198 & 6 & nest & 0.740740741 & 0.046 & 7 & Cyanobacteria/Chlo & roplast Chloroplas & ast $\quad-$ & Chloroplast & - \\
\hline Otu1239 & 6 & nest & 0.737179487 & 0.04 & 6 & Proteobacteria & Alphaproteobacteria & & - & - \\
\hline Otu182 & 6 & nest & 0.718343195 & 0.007 & 12 & Proteobacteria & Alphaproteobacteria & aCaulobacterales & Caulobacteraceae & Brevundimonas \\
\hline Otu4069 & 6 & nest & 0.702614379 & 0.038 & 6 & Actinobacteria & Actinobacteria & Actinomycetales & Mycobacteriaceae & Mycobacterium \\
\hline Otu1244 & 6 & nest & 0.666666667 & 0.048 & 6 & Proteobacteria & Alphaproteobacteria & aRhodospirillales & Acetobacteraceae & - \\
\hline Otu129 & 6 & nest & 0.666666667 & 0.048 & 4 & Proteobacteria & Alphaproteobacteria & & - & - \\
\hline Otu558 & 6 & nest & 0.666666667 & 0.049 & 4 & Proteobacteria & Alphaproteobacteria & aRhodospirillales & Rhodospirillaceae & - \\
\hline Otu885 & 6 & nest & 0.666666667 & 0.049 & 4 & TM7 & - & - & - & TM7_genera_incertae_sedis \\
\hline Otu2239 & 6 & nest & 0.666666667 & 0.043 & 4 & - & - & - & - & $-\quad-\infty \quad-+2-$ \\
\hline Otu3850 & 6 & nest & 0.666666667 & 0.049 & 4 & - & - & - & - & - \\
\hline Otu5356 & 6 & nest & 0.666666667 & 0.043 & 4 & - & - & - & - & - \\
\hline Otu988 & 6 & ref soils & 1 & 0.006 & 6 & Proteobacteria & Deltaproteobacteria & Myxococcales & - & - \\
\hline Otu1049 & 6 & ref soils & 1 & 0.008 & 6 & Armatimonadetes & - & - & - & Armatimonadetes_gp5 \\
\hline Otu690 & 6 & ref soils & 1 & 0.006 & 6 & Planctomycetes & Planctomycetacia & Planctomycetales & Planctomycetaceae & Zavarzinella \\
\hline Otu4161 & 6 & ref soils & 1 & 0.004 & 6 & Proteobacteria & Alphaproteobacteria & & - & - \\
\hline Otu193 & 6 & ref soils & 0.98828125 & 0.01 & 7 & Proteobacteria & Deltaproteobacteria & Myxococcales & Polyangiaceae & Byssovorax \\
\hline Otu202 & 6 & ref soils & 0.986486486 & 0.006 & 9 & Proteobacteria & Betaproteobacteria & Burkholderiales & - & - \\
\hline Otu2262 & 6 & ref soils & 0.983870968 & 0.002 & 8 & Proteobacteria & Betaproteobacteria & Burkholderiales & - & - \\
\hline Otu2760 & 6 & ref soils & 0.97761194 & 0.008 & 8 & Acidobacteria & Acidobacteria_Gp2 & - & - & Gp2 \\
\hline Otu242 & 6 & ref soils & 0.977011494 & 0.003 & 9 & Bacteroidetes & Sphingobacteria & Sphingobacteriales & Chitinophagaceae & - \\
\hline Otu213 & 6 & ref soils & 0.976331361 & 0.033 & 8 & Bacteroidetes & Sphingobacteria & Sphingobacteriales & Sphingobacteriacea & aeMucilaginibacter \\
\hline Otu1042 & 6 & ref soils & 0.975 & 0.008 & 7 & Bacteroidetes & Sphingobacteria & Sphingobacteriales & Chitinophagaceae & Ferruginibacter \\
\hline Otu215 & 6 & ref soils & 0.973451327 & 0.001 & 8 & Proteobacteria & Alphaproteobacteria & aRhodospirillales & Acetobacteraceae & Acidisphaera \\
\hline Otu83 & 6 & ref soils & 0.971175166 & 0.002 & 9 & Proteobacteria & Gammaproteobacter & ria- & - & - \\
\hline Otu1011 & 6 & ref soils & 0.970588235 & 0.01 & 7 & Armatimonadetes & - & - & - & Armatimonadetes_gp5 \\
\hline Otu40 & 6 & ref soils & 0.970123023 & 0.004 & 10 & Acidobacteria & Acidobacteria_Gp2 & - & - & Gp2 \\
\hline Otu1117 & 6 & ref soils & 0.958333333 & 0.006 & 7 & Acidobacteria & Acidobacteria_Gp5 & - & - & Gp5 \\
\hline Otu132 & 6 & ref soils & 0.956228956 & 0.043 & 10 & Actinobacteria & Actinobacteria & Actinomycetales & Microbacteriaceae & - \\
\hline Otu513 & 6 & ref soils & 0.951388889 & 0.024 & 8 & Acidobacteria & Acidobacteria_Gp1 & - & - & Gp1 \\
\hline Otu330 & 6 & ref soils & 0.949044586 & 0.031 & 9 & Acidobacteria & Acidobacteria_Gp1 & - & - & - \\
\hline Otu1061 & 6 & ref soils & 0.946236559 & 0.005 & 9 & Acidobacteria & Acidobacteria_Gp3 & - & - & Gp3 \\
\hline Otu128 & 6 & ref soils & 0.945632799 & 0.005 & 9 & Bacteroidetes & Sphingobacteria & Sphingobacteriales & Chitinophagaceae & - \\
\hline Otu85 & 6 & ref soils & 0.943462898 & 0.004 & 10 & Acidobacteria & Acidobacteria_Gp1 & - & - & Gp1 \\
\hline Otu1171 & 6 & ref soils & 0.941176471 & 0.011 & 7 & Proteobacteria & Deltaproteobacteria & Myxococcales & Polyangiaceae & Sorangium \\
\hline Otu1852 & 6 & ref soils & 0.935483871 & 0.002 & 8 & Bacteroidetes & Sphingobacteria & Sphingobacteriales & Chitinophagaceae & - \\
\hline Otu743 & 6 & ref soils & 0.933333333 & 0.006 & 8 & Acidobacteria & Acidobacteria_Gp3 & - & - & Gp3 \\
\hline Otu656 & 6 & ref soils & 0.931166348 & 0.006 & 10 & Acidobacteria & Acidobacteria_Gp1 & - & - & Gp1 \\
\hline Otu646 & 6 & ref soils & 0.926829268 & 0.002 & 9 & Bacteroidetes & Flavobacteria & Flavobacteriales & Flavobacteriaceae & - \\
\hline Otu64 & 6 & ref soils & 0.912225705 & 0.012 & 11 & Proteobacteria & Alphaproteobacteria & aRhizobiales & - & - \\
\hline Otu408 & 6 & ref soils & 0.911564626 & 0.007 & 8 & Verrucomicrobia & Opitutae & Opitutales & Opitutaceae & Opitutus \\
\hline Otu105 & 6 & ref soils & 0.909502262 & 0.02 & 11 & Verrucomicrobia & Opitutae & Opitutales & Opitutaceae & Opitutus \\
\hline Otu467 & 6 & ref soils & 0.908163265 & 0.028 & 9 & Acidobacteria & Acidobacteria_Gp3 & - & - & Gp3 \\
\hline Otu1207 & 6 & ref soils & 0.902439024 & 0.02 & 9 & Proteobacteria & Deltaproteobacteria & & - & - \\
\hline Otu62 & 6 & ref soils & 0.897923875 & 0.028 & 10 & Acidobacteria & Acidobacteria_Gp1 & - & - & Gp1 \\
\hline Otu103 & 6 & ref soils & 0.893243243 & 0.005 & 12 & Proteobacteria & Alphaproteobāacteria & aRhizobiales & - & - \\
\hline Otu714 & 6 & ref soils & 0.888157895 & 0.03 & 9 & Proteobacteria & Alphaproteobacteria & & - & - \\
\hline Otu190 & 6 & ref soils & 0.885416667 & 0.012 & 8 & Acidobacteria & Acidobacteria_Gp2 & - & - & Gp2 \\
\hline Otu364 & 6 & ref soils & 0.885245902 & 0.014 & 9 & Proteobacteria & Deltaproteobacteria & Myxococcales & Polyangiaceae & - \\
\hline Otu940 & 6 & ref soils & 0.881818182 & 0.007 & 10 & Actinobacteria & Actinobacteria & Acidimicrobiales & Acidimicrobineae_I.S & sAciditerrimonas \\
\hline Otu514 & 6 & ref soils & 0.879310345 & 0.004 & 10 & Proteobacteria & Alphaproteobacteria & aRhizobiales & - & - \\
\hline Otu911 & 6 & ref soils & 0.879032258 & 0.033 & 9 & - & - & - & - & - \\
\hline Otu459 & 6 & ref soils & 0.86746988 & 0.01 & 10 & Acidobacteria & Acidobacteria_Gp3 & - & - & Gp3 \\
\hline Otu682 & 6 & ref soils & 0.865671642 & 0.018 & 9 & Proteobacteria & Alphaproteobacteria & aRhizobiales & - & - \\
\hline Otu5 & 6 & ref soils & 0.86011657 & 0.044 & 12 & Proteobacteria & Alphaproteobacteria & aRhizobiales & - & - \\
\hline Otu16 & 6 & ref soils & 0.858229599 & 0.032 & 12 & Acidobacteria & Acidobacteria_Gp1 & - & - & Gp1 \\
\hline Otu203 & 6 & ref soils & 0.846153846 & 0.017 & 12 & Proteobacteria & Alphaproteobacteria & aRhodospirillales & Acetobacteraceae & - \\
\hline Otu874 & 6 & ref soils & 0.844919786 & 0.009 & 10 & Proteobacteria & Alphaproteobacteria & Rhizobiales & - & - \\
\hline Otu66 & 6 & ref soils & 0.843817787 & 0.027 & 11 & Acidobacteria & Acidobacteria_Gp2 & - & - & Gp2 \\
\hline Otu268 & 6 & ref soils & 0.843648208 & 0.006 & 11 & - & - & - & - & - \\
\hline Otu641 & 6 & ref soils & 0.835051546 & 0.019 & 11 & Proteobacteria & Alphaproteobacteria & & - & - \\
\hline Otu100 & 6 & ref soils & 0.833333333 & 0.017 & 5 & Bacteroidetes & Bacteroidetes_I.S & - & Ohtaekwangia & - \\
\hline Otu1400 & 6 & ref soils & 0.833333333 & 0.014 & 5 & - & - & - & - & - \\
\hline Otu1626 & 6 & ref soils & 0.833333333 & 0.014 & 5 & Verrucomicrobia & Opitutae & Opitutales & Opitutaceae & Opitutus \\
\hline Otu971 & 6 & ref soils & 0.833333333 & 0.016 & 5 & Acidobacteria & Acidobacteria_Gp2 & - & - & Gp2 \\
\hline Otu1251 & 6 & ref soils & 0.833333333 & 0.01 & 5 & Actinobacteria & Actinobacteria & Solirubrobacterales & - & - \\
\hline Otu2006 & 6 & ref soils & 0.833333333 & 0.017 & 5 & Proteobacteria & Deltaproteobacteria & Myxococcales & Cystobacteraceae & - \\
\hline Otu2422 & 6 & ref soils & 0.833333333 & 0.02 & 5 & - & - & - & - & - \\
\hline Otu2073 & 6 & ref soils & 0.833333333 & 0.01 & 5 & Proteobacteria & Deltaproteobacteria & Myxococcales & - & - \\
\hline Otu2945 & 6 & ref soils & 0.833333333 & 0.023 & 5 & Bacteroidetes & - & - & - & - \\
\hline Otu2212 & 6 & ref soils & 0.833333333 & 0.011 & 5 & Planctomycetes & Planctomycetacia & Planctomycetales & Planctomycetaceae & - \\
\hline
\end{tabular}


Otu4742 6

Otu3938 6

Otu2448 6

Otu74 6

Otu134 6

Otu523 6

Otu409 6

Otu503 6

Otu363 6

Otu1250 6

Otu26 6

Otu759 6

Otu2480 6

Otu2301 6

Otu1487 6

Otu1610 6

Otu1369 6

Otu1076 6

Otu67 6

Otu1014 6

Otu565 6

Otu341 6

Otu1594 6

Otu1081 6

Otu6 6

Otu844 6

Otu2180 6

Otu1939 6

Otu592 6

Otu238 6

Otu2632 6

Otu326 6

Otu1697 6

Otu3030 6

Otu951 6

Otu1295 6

Otu1261 6

Otu2326 6

Otu65 6

Otu1329 8

Otu201 8

Otu78 8

Otu79 8

Otu122 8

Otu245 8

Otu191 8

Otu643 8

Otu181 8

Otu156 8

Otu794 8

Otu5290 8

Otu129 8

Otu59 8

Otu573 8

Otu450 8

Otu175 8

Otu675 8

Otu110 8

Otu139 8

Otu1911 8

Otu36 8

Otu545 8

Otu2036 8

Otu385 8

Otu10 8

Otu403 8

Otu2568 8

Otu112 8

Otu745 8

Otu1312 8

Otu3525 8

Otu38 8

Otu827 8

Otu1595 8

Otu2489 8

Otu4717 8

Otu182 8

Otu235 8

Otu2731 8

Otu499 8

Otu517 8 ref soils $\quad 0.833333333$

ref soils 0.833333333

ref soils 0.833333333

ref soils $\quad 0.82934927$

ref soils $\quad 0.829099307$

ref soils $\quad 0.825688073$

ref soils $\quad 0.825346113$

ref soils 0.825

ref soils $\quad 0.822368421$

ref soils $\quad 0.817307692$

ref soils $\quad 0.812138728$

ref soils $\quad 0.811965812$

ref soils $\quad 0.80952381$

ref soils $\quad 0.807692308$

ref soils $\quad 0.806878307$

ref soils $\quad 0.804597701$

ref soils 0.802469136

ref soils 0.8

ref soils $\quad 0.785930663$

ref soils $\quad 0.784132841$

ref soils $\quad 0.783505155$

ref soils $\quad 0.782258065$

ref soils $\quad 0.777027027$

ref soils $\quad 0.777027027$

ref soils $\quad 0.776859504$

ref soils $\quad 0.773809524$

ref soils $\quad 0.769230769$

ref soils 0.763888889

ref soils $\quad 0.757575758$

ref soils $\quad 0.757142857$

ref soils $\quad 0.756756757$

ref soils $\quad 0.748945148$

ref soils $\quad 0.689655172$

ref soils $\quad 0.666666667$

ref soils 0.666666667

ref soils $\quad 0.666666667$

ref soils 0.666666667

ref soils $\quad 0.666666667$

ref soils 0.637189794

nest 1

nest 0.999289773

nest 0.99824561

nest 0.995043047

nest 0.992125984

nest 0.990074442

nest 0.987113402

nest 0.983050847

nest 0.979539642

nest 0.979338843

nest $\quad 0.974358974$

nest 0.973684211

nest $\quad 0.973568282$

nest $\quad 0.973194341$

nest 0.973154362

nest 0.972477064

nest 0.967914439

nest 0.961290323

nest 0.956937799

nest 0.956923077

nest 0.95483871

nest $\quad 0.949644226$

nest 0.943089431

nest 0.93814433

nest $\quad 0.9375$

nest $\quad 0.934791414$

nest $\quad 0.931558935$

nest 0.928571429

nest 0.922619048

nest $\quad 0.92251816$

nest 0.915966387

nest 0.911917098

nest $\quad 0.907180385$

nest $\quad 0.895833333$

nest 0.888888889

nest 0.886666667

nest $\quad 0.866666667$

nest $\quad 0.860692771$

nest 0.84981685

nest $\quad 0.846153846$

nest $\quad 0.843373494$

nest 0.833333333

Chapterll_Lindström_et_al_2019_in_press_suppl_Table S4

0.0175

Bacteroidetes

Proteobacteria

Proteobacteria

Bacteroidetes

Proteobacteria

Proteobacteria

Proteobacteria

Bacteroidetes

Proteobacteria

Acidobacteria

Proteobacteria

Bacteroidetes

Bacteroidetes

Bacteroidetes

Proteobacteria

Proteobacteria

Acidobacteria

Proteobacteria

Verrucomicrobia

Acidobacteria

Proteobacteria

Proteobacteria

Bacteroidetes

Acidobacteria

Proteobacteria

Proteobacteria

Proteobacteria

Proteobacteria

Armatimonadetes

Proteobacteria

Bacteroidetes

Bacteroidetes

Proteobacteria

Actinobacteria

Proteobacteria

Proteobacteria

Acidobacteria

Actinobacteria

Actinobacteria

Proteobacteria

Bacteroidetes

Proteobacteria

Actinobacteria

Actinobacteria

Proteobacteria

Actinobacteria

Actinobacteria

Proteobacteria

Proteobacteria

Proteobacteria

Actinobacteria

Proteobacteria

Proteobacteria

Proteobacteria

Acidobacteria

Proteobacteria

Cyanobacteria

Actinobacteria

Proteobacteria

Proteobacteria

Actinobacteria

Proteobacteria

Proteobacteria

Acidobacteria

Actinobacteria

Proteobacteria

Proteobacteria

Proteobacteria

Proteobacteria

Actinobacteria

Proteobacteria

Cyanobacteria

Actinobacteria

AlphaproteobacteriaRhodospirillales

Sphingobacteria Sphingobacteriales Chitinophagaceae

AlphaproteobacteriaRhodospirillales Acetobacteraceae

Gammaproteobacteria

AlphaproteobacteriaRhodospirillales

Alphaproteobacteria-

Acidobacteria Gp2

Gp2

AlphaproteobacteriaRhodospirillales Acetobacteraceae

Sphingobacteria Sphingobacteriales Sphingobacteriaceae Mucilaginibacter

Sphingobacteria Sphingobacteriales Chitinophagaceae

Alphaproteobacteria-

Acidobacteria Gp1

Betaproteobacteria Burkholderiales Burkholderiales_I.s

Opitutae Opitutales Opitutaceae Opitutus

Acidobacteria_Gp3 - $\quad$ - $\quad$ Gp3

GammaproteobacteriaXanthomonadalesXanthomonadaceaeRudaea

Gammaproteobacteria

Sphingobacteria Sphingobacteriales Chitinophagaceae Segetibacter

Acidobacteria_Gp3 -

Gp3

Comamonadaceae Pelomonas

AlphaproteobacteriaRhodospirillales Acetobacteraceae

Alphaproteobacteria

GammaproteobacteriaXanthomonadalesSinobacteraceae Nevskia

Armatimonadetes gp5

Sphingobacteria Sphingobacteriales $\bar{C}$ Chitinophagaceae

Sphingobacteria Sphingobacteriales Chitinophagaceae

AlphaproteobacteriaCaulobacterales Caulobacteraceae Caulobacter

Actinobacteria Actinomycetales PseudonocardiaceaeActinomycetospora

Betaproteobacteria Burkholderiales Oxalobacteraceae Massilia

Betaproteobacteria Burkholderiales Oxalobacteraceae Massilia

Acidobacteria Gp1 .

Actinobacteria Actinomycetales

Actinobacteria Actinomycetales

AlphaproteobacteriaRhodospirillales

Sphingobacteria Sphingobacteriales

AlphaproteobacteriaRhizobiales

Actinobacteria Actinomycetales

Actinobacteria Actinomycetales

Alphaproteobacteria-

Actinobacteria Actinomycetales

Actinobacteria Actinomycetales

Alphaproteobacteria-

AlphaproteobacteriaRhizobiales

AlphaproteobacteriaRhodospirillales

Actinobacteria Actinomycetales

Betaproteobacteria Burkholderiales

AlphaproteobacteriaRhizobiales

AlphaproteobacteriaRhizobiales

Acidobacteria Gp1

AlphaproteobacteriaRhizobiales

Chloroplast

Actinobacteria Actinomycetales

Deltaproteobacteria -

AlphaproteobacteriaRhizobiales

Actinobacteria Actinomycetales 


\begin{tabular}{|c|c|c|c|c|}
\hline Otu183 & 8 & nest & 0.833333333 & 0.02 \\
\hline Otu1824 & 8 & nest & 0.833333333 & 0.007 \\
\hline Otu1409 & 8 & nest & 0.833333333 & 0.014 \\
\hline Otu2136 & 8 & nest & 0.833333333 & 0.019 \\
\hline Otu2162 & 8 & nest & 0.833333333 & 0.016 \\
\hline Otu1239 & 8 & nest & 0.833333333 & 0.024 \\
\hline Otu2735 & 8 & nest & 0.833333333 & 0.017 \\
\hline Otu4037 & 8 & nest & 0.833333333 & 0.015 \\
\hline Otu3364 & 8 & nest & 0.833333333 & 0.017 \\
\hline Otu41 & 8 & nest & 0.829749104 & 0.036 \\
\hline Otu283 & 8 & nest & 0.829383886 & 0.035 \\
\hline Otu1677 & 8 & nest & 0.825545171 & 0.02 \\
\hline Otu277 & 8 & nest & 0.82537155 & 0.047 \\
\hline Otu4126 & 8 & nest & 0.820707071 & 0.033 \\
\hline Otu722 & 8 & nest & 0.811594203 & 0.037 \\
\hline Otu368 & 8 & nest & 0.810606061 & 0.045 \\
\hline Otu2587 & 8 & nest & 0.808823529 & 0.022 \\
\hline Otu166 & 8 & nest & 0.806781046 & 0.038 \\
\hline Otu2975 & 8 & nest & 0.803370787 & 0.033 \\
\hline Otu1604 & 8 & nest & 0.801282051 & 0.023 \\
\hline Otu1481 & 8 & nest & 0.801282051 & 0.04 \\
\hline Otu2349 & 8 & nest & 0.8 & 0.025 \\
\hline Otu303 & 8 & nest & 0.794797688 & 0.05 \\
\hline Otu3254 & 8 & nest & 0.78125 & 0.049 \\
\hline Otu91 & 8 & nest & 0.781032078 & 0.043 \\
\hline Otu2151 & 8 & nest & 0.773809524 & 0.014 \\
\hline Otu324 & 8 & nest & 0.772569444 & 0.041 \\
\hline Otu195 & 8 & nest & 0.763656633 & 0.034 \\
\hline Otu153 & 8 & nest & 0.761862131 & 0.05 \\
\hline Otu92 & 8 & nest & 0.736111111 & 0.01 \\
\hline Otu1832 & 8 & nest & 0.6666666667 & 0.045 \\
\hline Otu1742 & 8 & nest & 0.6666666667 & 0.048 \\
\hline Otu236 & 8 & nest & 0.664215686 & 0.042 \\
\hline Otu1539 & 8 & nest & 0.631578947 & 0.049 \\
\hline Otu242 & 8 & ref soils & 1 & 0.002 \\
\hline Otu1042 & 8 & ref soils & 1 & 0.004 \\
\hline Otu929 & 8 & ref soils & 1 & 0.002 \\
\hline Otu193 & 8 & ref soils & 1 & 0.006 \\
\hline Otu1759 & 8 & ref soils & 1 & 0.003 \\
\hline Otu808 & 8 & ref soils & 1 & 0.003 \\
\hline Otu1497 & 8 & ref soils & 1 & 0.005 \\
\hline Otu503 & 8 & ref soils & 1 & 0.003 \\
\hline Otu1117 & 8 & ref soils & 1 & 0.005 \\
\hline Otu986 & 8 & ref soils & 1 & 0.004 \\
\hline Otu3026 & 8 & ref soils & 1 & 0.004 \\
\hline Otu3738 & 8 & ref soils & 1 & 0.003 \\
\hline Otu2006 & 8 & ref soils & 1 & 0.004 \\
\hline Otu1296 & 8 & ref soils & 1 & 0.004 \\
\hline Otu1249 & 8 & ref soils & 1 & 0.004 \\
\hline Otu776 & 8 & ref soils & 1 & 0.003 \\
\hline Otu596 & 8 & ref soils & 1 & 0.002 \\
\hline Otu3694 & 8 & ref soils & 1 & 0.005 \\
\hline Otu1982 & 8 & ref soils & 1 & 0.002 \\
\hline Otu306 & 8 & ref soils & 0.993670886 & 0.006 \\
\hline Otu4382 & 8 & ref soils & 0.99122807 & 0.002 \\
\hline Otu83 & 8 & ref soils & 0.988970588 & 0.004 \\
\hline Otu1365 & 8 & ref soils & 0.9875 & 0.002 \\
\hline Otu2077 & 8 & ref soils & 0.987341772 & 0.002 \\
\hline Otu694 & 8 & ref soils & 0.986842105 & 0.001 \\
\hline Otu1852 & 8 & ref soils & 0.985915493 & 0.007 \\
\hline Otu246 & 8 & ref soils & 0.985294118 & 0.005 \\
\hline Otu2928 & 8 & ref soils & 0.983050847 & 0.003 \\
\hline Otu149 & 8 & ref soils & 0.982608696 & 0.034 \\
\hline Otu377 & 8 & ref soils & 0.981132075 & 0.002 \\
\hline Otu765 & 8 & ref soils & 0.978723404 & 0.005 \\
\hline Otu641 & 8 & ref soils & 0.978723404 & 0.002 \\
\hline Otu467 & 8 & ref soils & 0.974193548 & 0.003 \\
\hline Otu128 & 8 & ref soils & 0.972519084 & 0.006 \\
\hline Otu26 & 8 & ref soils & 0.968512486 & 0.004 \\
\hline Otu1250 & 8 & ref soils & 0.967741935 & 0.007 \\
\hline Otu2534 & 8 & ref soils & 0.967741935 & 0.004 \\
\hline Otu1527 & 8 & ref soils & 0.966666667 & 0.002 \\
\hline Otu1061 & 8 & ref soils & 0.964285714 & 0.005 \\
\hline Otu451 & 8 & ref soils & 0.96350365 & 0.002 \\
\hline Otu911 & 8 & ref soils & 0.962732919 & 0.003 \\
\hline Otu1426 & 8 & ref soils & 0.961325967 & 0.002 \\
\hline Otu479 & 8 & ref soils & 0.96 & 0.006 \\
\hline Otu851 & 8 & ref soils & 0.958333333 & 0.006 \\
\hline Otu2288 & 8 & ref soils & 0.958333333 & 0.01 \\
\hline Otu2900 & 8 & ref soils & 0.956521739 & 0.008 \\
\hline Otu1102 & 8 & ref soils & 0.954545455 & 0.007 \\
\hline
\end{tabular}

Chapterll_Lindström_et_al_2019_in_press_suppl_Table S4

$\begin{array}{lll}\text { Actinobacteria } & \text { Actinobacteria Actinomycetales } & \\ \text { Proteobacteria } & \text { AlphaproteobacteriaRhodospirillales } & \text { Acet } \\ \text { Proteobacteria } & \text { AlphaproteobacteriaRhodospirillales } & \text { Acet } \\ \text { - } & \text { - } & \text { - } \\ \text { Proteobacteria } & \text { AlphaproteobacteriaRhodospirillales } & \text { Aceteria } \\ \text { Proteobacteria } & \text { Alphaproteobacteria- } & \text { - } \\ \text { Proteobacteria } & \text { Deltaproteobacteria - } & \text { - } \\ \text { - } & \text { - } & \text { - }\end{array}$

Proteobacteria

Actinobacteria

Proteobacteria

Actinobacteria

Proteobacteria

Proteobacteria

Cyanobacteria/C

Actinobacteria

Proteobacteria

Acidobacteria

TM7

TM7

Actinobacteria

Proteobacteria

Actinobacteria

Planctomycetes

Actinobacteria

Actinobacteria

Acidobacteria

Proteobacteria

Actinobacteria

$-$

Bacteroidetes

Bacteroidetes

Bacteroidetes

Proteobacteria

Acidobacteria

Planctomycetes

Acidobacteria

Acidobacteria

Armatimonadetes

Planctomycetes

Proteobacteria

Bacteroidetes

Proteobacteria

Bacteroidetes

Proteobacteria

Armatimonadetes

Planctomycetes

Proteobacteria

Bacteroidetes

Proteobacteria

Acidobacteria

Planctomycetes

Bacteroidetes

Bacteroidetes

Bacteroidetes

Proteobacteria

Proteobacteria

Proteobacteria

Proteobacteria

Proteobacteria

Acidobacteria

Bacteroidetes

Proteobacteria

Bacteroidetes

Actinobacteria

Proteobacteria

Acidobacteria

Proteobacteria

Acidobacteria

Proteobacteria

Proteobacteria

Planctomycetes

Planctomycetes Armatimonadetes

Actinobacteria Actinomycetales -

Betaproteobacteria Burkholderiales

Alphaproteobacteria-

roplast Chloroplast

Acidobacteria_Gp1 .

-

Actinobacteria Solirubrobacterales -

AlphaproteobacteriaRhizobiales

Acidobacteria Gp1 -

-

Acidobacteria_Gp3 -

Acidobacteria_Gp5 -

Acidobacteria Gp3 -

Betaproteobacteria -

Alphaproteobacteria-

Gammaproteobacteria

Acidobacteria_Gp1 -

Alphaproteobacteria-

GammaproteobacteriaPseudomonadales

Deltaproteobacteria Myxococcales

Deltaproteobacteria Myxococcales

Alphaproteobacteria-

Acidobacteria_Gp3 -

Alphaproteobacteria-

Actinobacteria $\quad$ Actinomycetales

Alphaproteobacteria-

Acidobacteria Gp3 -

Acidobacteria Gp3 -
Microbacteriaceae -

Acetobacteraceae

Acetobacteraceae

Acetobacteraceae

-

Planctomycetacia Planctomycetales Planctomycetaceae Singulisphaera

Betaproteobacteria Burkholderiales Burkholderiaceae Burkholderia

Actinobacteria Actinomycetales Streptomycetaceae Streptomyces

AlphaproteobacteriaRhizobiales Methylocystaceae Methylocystis

Actinobacteria Actinomycetales Chloroplast

AlphaproteobacteriaRhodospirillales Acetobacteraceae

Granulicella

TM7_genera_I.S

TM7_genera_I.S

Actinobacteria Actinomycetales Pseudonocardiaceae Pseudonocardia

Planctomycetacia Planctomycetales Planctomycetaceae Singulisphaera

Actinobacteria - $\quad$ -

Actinobacteria Actinomycetales Mycobacteriaceae Mycobacterium

AlphaproteobacteriaSphingomonadales Sphingomonadaceae-

Actinobacteria Actinomycetales Streptomycetaceae Streptomyces

Sphingobacteria Sphingobacteriales Chitinophagaceae -

Sphingobacteria Sphingobacteriales Chitinophagaceae Ferruginibacter

Sphingobacteria Sphingobacteriales Chitinophagaceae -

Deltaproteobacteria Myxococcales Polyangiaceae Byssovorax

Gp3

Planctomycetacia Planctomycetales Planctomycetaceae Schlesneria

Gp5

Gp3

Armatimonadia Armatimonadales Armatimonadaceae Armatimonadetes_gp1

Planctomycetacia Planctomycetales Planctomycetaceae -

Deltaproteobacteria Myxococcales Cystobacteraceae -

Sphingobacteria Sphingobacteriales Chitinophagaceae -

Sphingobacteria Sphingobacteriales Chitinophagaceae.

Chthonomonadetes Chthonomonadales Chthonomonadaceae Armatimonadetes_gp3

Planctomycetacia Planctomycetales Planctomycetaceae Gemmata

Deltaproteobacteria Myxococcales Kofleriaceae Kofleria

Sphingobacteria Sphingobacteriales Chitinophagaceae -

Planctomycetacia Planctomycetales Planctomycetaceae Schlesneria

Sphingobacteria Sphingobacteriales Chitinophagaceae Ferruginibacter

Sphingobacteria Sphingobacteriales Chitinophagaceae -

Sphingobacteria Sphingobacteriales Chitinophagaceae -

Sphingobacteria Sphingobacteriales Chitinophagaceae -

Pseudomonadaceae Pseudomonas

-

AlphaproteobacteriaRhizobiales Xanthobacteraceae Labrys

GammaproteobacteriaXanthomonadalesSinobacteraceae Nevskia

Planctomycetacia Planctomycetales Planctomycetaceae Singulisphaera

Planctomycetacia Planctomycetales Planctomycetaceae Gemmata 


\begin{tabular}{|c|c|c|c|c|c|c|c|c|c|c|}
\hline \multicolumn{11}{|c|}{ cnapteril_Linastrom_et_al_zU19_In_press_suppl_Iable s4 } \\
\hline Otu357 & 8 & ref soils & 0.953736655 & 0.002 & 10 & Proteobacteria & \multicolumn{2}{|c|}{ Deltaproteobacteria Myxococcales } & - & - \\
\hline Otu743 & 8 & ref soils & 0.952380952 & 0.012 & 8 & Acidobacteria & \multicolumn{2}{|c|}{ Acidobacteria_Gp3 - } & - & Gp3 \\
\hline Otu656 & 8 & ref soils & 0.950576606 & 0.006 & 10 & Acidobacteria & Acidobacteria_Gp1 & & - & Gp1 \\
\hline Otu85 & 8 & ref soils & 0.949675325 & 0.008 & 10 & Acidobacteria & Acidobacteria_Gp1 & & - & Gp1 \\
\hline Otu84 & 8 & ref soils & 0.947666195 & 0.039 & 9 & Proteobacteria & Gammaproteobacte & riaXanthomonadales & sXanthomonadaceae & \\
\hline Otu1600 & 8 & ref soils & 0.942857143 & 0.016 & 9 & Actinobacteria & Actinobacteria & Actinomycetales & Catenulisporaceae & Catenulispora \\
\hline Otu459 & 8 & ref soils & 0.942028986 & 0.004 & 9 & Acidobacteria & Acidobacteria_Gp3 & - & - & Gp3 \\
\hline Otu40 & 8 & ref soils & 0.940184049 & 0.028 & 9 & Acidobacteria & Acidobacteria_Gp2 & - & - & Gp2 \\
\hline Otu215 & 8 & ref soils & 0.93956044 & 0.007 & 8 & Proteobacteria & Alphaproteobacteria & aRhodospirillales & Acetobacteraceae & Acidisphaera \\
\hline Otu317 & 8 & ref soils & 0.935828877 & 0.03 & 11 & Proteobacteria & Gammaproteobacte & & - & - \\
\hline Otu268 & 8 & ref soils & 0.931558935 & 0.017 & 10 & - & - & - & - & - \\
\hline Otu644 & 8 & ref soils & 0.928888889 & 0.02 & 9 & Proteobacteria & Gammaproteobacte & riaXanthomonadales & sXanthomonadaceae & eRudaea \\
\hline Otu103 & 8 & ref soils & 0.923428571 & 0.008 & 9 & Proteobacteria & Alphaproteobacteria & aRhizobiales & - & - \\
\hline Otu227 & 8 & ref soils & 0.922413793 & 0.008 & 10 & Acidobacteria & Acidobacteria_Gp1 & - & - & - \\
\hline Otu2396 & 8 & ref soils & 0.92 & 0.015 & 8 & Planctomycetes & Planctomycetacia & Planctomycetales & Planctomycetaceae & - \\
\hline Otu3871 & 8 & ref soils & 0.918367347 & 0.04 & 9 & Acidobacteria & Acidobacteria_Gp3 & - & - & Gp3 \\
\hline Otu638 & 8 & ref soils & 0.917197452 & 0.029 & 11 & Proteobacteria & Alphaproteobācteria & aRhizobiales & - & - \\
\hline Otu785 & 8 & ref soils & 0.914529915 & 0.031 & 10 & - & - & - & - & - \\
\hline Otu134 & 8 & ref soils & 0.911147011 & 0.006 & 11 & Bacteroidetes & Sphingobacteria & Sphingobacteriales & Chitinophagaceae & - \\
\hline Otu16 & 8 & ref soils & 0.91053787 & 0.027 & 10 & Acidobacteria & Acidobacteria_Gp1 & - & - & Gp1 \\
\hline Otu1422 & 8 & ref soils & 0.909090909 & 0.008 & 8 & Bacteroidetes & Sphingobacteria & Sphingobacteriales & Chitinophagaceae & - \\
\hline Otu214 & 8 & ref soils & 0.908847185 & 0.016 & 11 & Bacteroidetes & Sphingobacteria & Sphingobacteriales & Chitinophagaceae & - \\
\hline Otu1207 & 8 & ref soils & 0.904761905 & 0.015 & 8 & Proteobacteria & Deltaproteobacteria & & - & - \\
\hline Otu287 & 8 & ref soils & 0.903846154 & 0.007 & 11 & Actinobacteria & Actinobacteria & Actinomycetales & Sporichthyaceae & Sporichthya \\
\hline Otu62 & 8 & ref soils & 0.898969072 & 0.006 & 9 & Acidobacteria & Acidobacteria_Gp1 & - & - & Gp1 \\
\hline Otu565 & 8 & ref soils & 0.894736842 & 0.009 & 11 & Verrucomicrobia & Opitutae & Opitutales & Opitutaceae & Opitutus \\
\hline Otu67 & 8 & ref soils & 0.89071618 & 0.008 & 11 & Acidobacteria & Acidobacteria_Gp1 & - & - & Gp1 \\
\hline Otu387 & 8 & ref soils & 0.887733888 & 0.036 & 11 & Acidobacteria & Acidobacteria_Gp1 & - & - & Gp1 \\
\hline Otu3449 & 8 & ref soils & 0.884615385 & 0.011 & 7 & Bacteroidetes & Sphingobacteria & Sphingobacteriales & Sphingobacteriacea & ae Mucilaginibacter \\
\hline Otu43 & 8 & ref soils & 0.882352941 & 0.036 & 10 & Bacteroidetes & Sphingobacteria & Sphingobacteriales & Sphingobacteriacea & ae Mucilaginibacter \\
\hline Otu87 & 8 & ref soils & 0.88185654 & 0.033 & 9 & Proteobacteria & Alphaproteobacteria & aRhodospirillales & Rhodospirillaceae & Telmatospirillum \\
\hline Otu25 & 8 & ref soils & 0.881795196 & 0.007 & 11 & Acidobacteria & Acidobacteria_Gp1 & & - & Gp1 \\
\hline Otu421 & 8 & ref soils & 0.88 & 0.015 & 11 & Proteobacteria & Gammaproteobacte & & - & - \\
\hline Otu6 & 8 & ref soils & 0.87661895 & 0.01 & 11 & Proteobacteria & Gammaproteobacte & & - & - \\
\hline Otu2477 & 8 & ref soils & 0.875 & 0.008 & 8 & Proteobacteria & Alphaproteobacteria & & - & - \\
\hline Otu972 & 8 & ref soils & 0.873563218 & 0.016 & 11 & Actinobacteria & Actinobacteria & Acidimicrobiales & Iamiaceae & lamia \\
\hline Otu566 & 8 & ref soils & 0.869565217 & 0.008 & 10 & Proteobacteria & Alphaproteobacteria & & - & - \\
\hline Otu238 & 8 & ref soils & 0.868471954 & 0.004 & 12 & Proteobacteria & Alphaproteobacteria & aRhodospirillales & Acetobacteraceae & - \\
\hline Otu431 & 8 & ref soils & 0.865591398 & 0.038 & 9 & Acidobacteria & Acidobacteria_Gp1 & - & - & Gp1 \\
\hline Otu89 & 8 & ref soils & 0.858483755 & 0.02 & 11 & Acidobacteria & Acidobacteria_Gp1 & - & - & Gp1 \\
\hline Otu203 & 8 & ref soils & 0.85046729 & 0.014 & 10 & Proteobacteria & Alphaproteobacteria & aRhodospirillales & Acetobacteraceae & - \\
\hline Otu1189 & 8 & ref soils & 0.848605578 & 0.021 & 10 & Proteobacteria & Alphaproteobacteria & aRhodospirillales & Acetobacteraceae & - \\
\hline Otu68 & 8 & ref soils & 0.841269841 & 0.032 & 11 & Actinobacteria & Actinobacteria & Actinomycetales & - & - \\
\hline Otu399 & 8 & ref soils & 0.83974359 & 0.019 & 11 & Bacteroidetes & Sphingobacteria & Sphingobacteriales & Chitinophagaceae & Segetibacter \\
\hline Otu1014 & 8 & ref soils & 0.833333333 & 0.016 & 5 & Proteobacteria & Betaproteobacteria & Burkholderiales & Burkholderiales_I.s & - \\
\hline Otu1011 & 8 & ref soils & 0.833333333 & 0.019 & 5 & Armatimonadetes & - & - & - $\quad$ Armatimon & nadetes_gp5 \\
\hline Otu619 & 8 & ref soils & 0.833333333 & 0.013 & 5 & Proteobacteria & Deltaproteobacteria & Myxococcales & Cystobacteraceae & Anaeromyxobacter \\
\hline Otu752 & 8 & ref soils & 0.833333333 & 0.008 & 5 & Proteobacteria & Betaproteobacteria & - & - & - \\
\hline Otu2717 & 8 & ref soils & 0.833333333 & 0.018 & 5 & Proteobacteria & Deltaproteobacteria & Myxococcales & $-\quad \quad-$ & - \\
\hline Otu3083 & 8 & ref soils & 0.833333333 & 0.019 & 5 & Proteobacteria & Gammaproteobacte & riaXanthomonadales & sXanthomonadaceae & e- \\
\hline Otu712 & 8 & ref soils & 0.833333333 & 0.017 & 5 & Verrucomicrobia & Opitutae & Opitutales & Opitutaceae & Opitutus \\
\hline Otu2262 & 8 & ref soils & 0.833333333 & 0.013 & 5 & Proteobacteria & Betaproteobacteria & Burkholderiales & - & - \\
\hline Otu1710 & 8 & ref soils & 0.833333333 & 0.02 & 5 & Proteobacteria & Gammaproteobacte & riaXanthomonadales & sXanthomonadaceae & e- \\
\hline Otu1072 & 8 & ref soils & 0.833333333 & 0.012 & 5 & Proteobacteria & - & - & - & - \\
\hline Otu1218 & 8 & ref soils & 0.833333333 & 0.01 & 5 & Proteobacteria & Gammaproteobacte & riaXanthomonadales & sXanthomonadaceae & e- \\
\hline Otu526 & 8 & ref soils & 0.833333333 & 0.018 & 5 & Proteobacteria & Alphaproteobacteria & aRhodospirillales & Rhodospirillaceae & - \\
\hline Otu3064 & 8 & ref soils & 0.833333333 & 0.018 & 5 & Planctomycetes & Planctomycetacia & Planctomycetales & Planctomycetaceae & Schlesneria \\
\hline Otu2073 & 8 & ref soils & 0.833333333 & 0.014 & 5 & Proteobacteria & Deltaproteobacteria & Myxococcales & - & - \\
\hline Otu798 & 8 & ref soils & 0.833333333 & 0.021 & 5 & Bacteroidetes & Sphingobacteria & Sphingobacteriales & Chitinophagaceae & - \\
\hline Otu1701 & 8 & ref soils & 0.833333333 & 0.019 & 5 & Proteobacteria & Deltaproteobacteria & Myxococcales & Polyangiaceae & - \\
\hline Otu3150 & 8 & ref soils & 0.833333333 & 0.013 & 5 & Planctomycetes & Planctomycetacia & Planctomycetales & Planctomycetaceae & Singulisphaera \\
\hline Otu4022 & 8 & ref soils & 0.833333333 & 0.018 & 5 & Acidobacteria & Acidobacteria_Gp3 & - & - & Gp3 \\
\hline Otu2322 & 8 & ref soils & 0.833333333 & 0.019 & 5 & Armatimonadetes & $-\quad$ & - & - & Armatimonadetes_gp5 \\
\hline Otu1504 & 8 & ref soils & 0.833333333 & 0.014 & 5 & Proteobacteria & Alphaproteobacteria & & - & - \\
\hline Otu2172 & 8 & ref soils & 0.833333333 & 0.018 & 5 & Proteobacteria & Gammaproteobacte & riaXanthomonadales & sXanthomonadaceae & e- \\
\hline Otu1330 & 8 & ref soils & 0.833333333 & 0.016 & 5 & Proteobacteria & Alphaproteobacteria & aCaulobacterales & Caulobacteraceae & Asticcacaulis \\
\hline Otu2632 & 8 & ref soils & 0.833333333 & 0.016 & 5 & Proteobacteria & Alphaproteobacteria & & - & - \\
\hline Otu1377 & 8 & ref soils & 0.833333333 & 0.013 & 5 & Bacteroidetes & - & - & - & - \\
\hline Otu1522 & 8 & ref soils & 0.833333333 & 0.021 & 5 & Proteobacteria & Alphaproteobacteria & & - & - \\
\hline Otu1626 & 8 & ref soils & 0.833333333 & 0.017 & 5 & Verrucomicrobia & Opitutae & Opitutales & Opitutaceae & Opitutus \\
\hline Otu2374 & 8 & ref soils & 0.833333333 & 0.021 & 5 & Proteobacteria & Alphaproteobacteria & Rhizobiales & - & - \\
\hline Otu1054 & 8 & ref soils & 0.833333333 & 0.016 & 5 & Planctomycetes & Phycisphaerae & Phycisphaerales & Phycisphaeraceae & Phycisphaera \\
\hline Otu3268 & 8 & ref soils & 0.833333333 & 0.015 & 5 & Planctomycetes & Planctomycetacia & Planctomycetales & Planctomycetaceae & - \\
\hline Otu5588 & 8 & ref soils & 0.833333333 & 0.023 & 5 & - & - & - & - & - \\
\hline Otu4463 & 8 & ref soils & 0.833333333 & 0.014 & 5 & Proteobacteria & Alphaproteobacteria & aRhodospirillales & - & - \\
\hline Otu3215 & 8 & ref soils & 0.833333333 & 0.021 & 5 & Planctomycetes & Planctomycetacia & Planctomycetales & Planctomycetaceae & Gemmata \\
\hline Otu4952 & 8 & ref soils & 0.833333333 & 0.017 & 5 & Acidobacteria & Acidobacteria_Gp2 & - & - & Gp2 \\
\hline Otu2272 & 8 & ref soils & 0.833333333 & 0.011 & 5 & Planctomycetes & Planctomycetāia & Planctomycetales & Planctomycetaceae & Gemmata \\
\hline Otu3736 & 8 & ref soils & 0.833333333 & 0.016 & 5 & - & - & - & - & - \\
\hline Otu2351 & 8 & ref soils & 0.833333333 & 0.011 & 5 & Proteobacteria & Deltaproteobacteria & Myxococcales & Polyangiaceae & - \\
\hline Otu874 & 8 & ref soils & 0.831050228 & 0.01 & 9 & Proteobacteria & Alphaproteobacteria & Rhizobiales & - & - \\
\hline
\end{tabular}




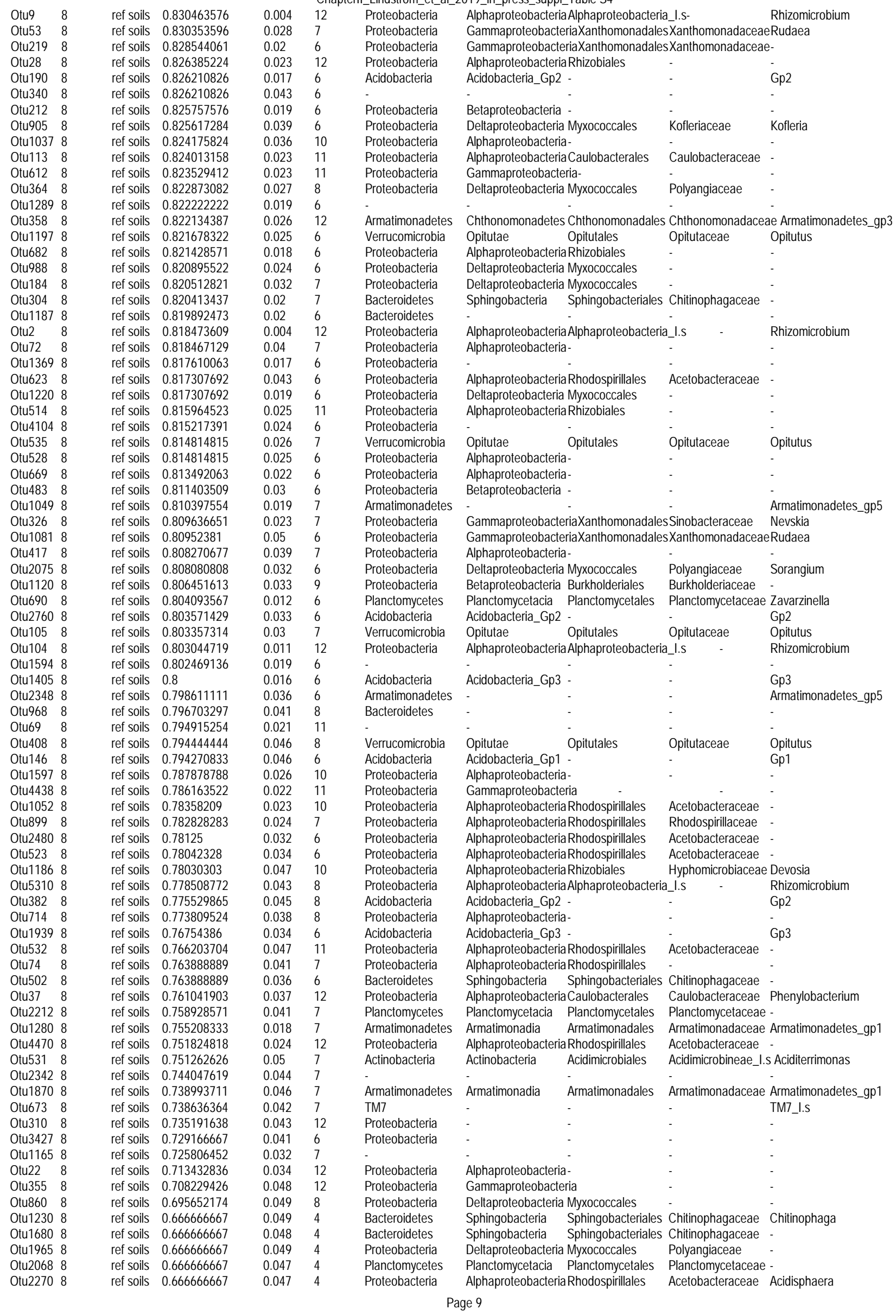


$\begin{array}{llll}\text { Otu2355 } 8 \quad \text { ref soils } & 0.666666667\end{array}$

$\begin{array}{llll}\text { Otu1 } 8 & \text { ref soils } & 0.641086102\end{array}$

ref soils 0.637681159

0.042

Chapterll_Lindström_et_al_2019_in_press_suppl_Table S4

Otu1468

$0.048-4 \quad$ Proteobacteria

$0.018 \quad 12 \quad$ Proteobacteria

$0.043 \quad 5 \quad$ Proteobacteria

AlphaproteobacteriaRhizobiales

Deltaproteobacteria Myxococcales

Bradyrhizobiaceae -

Polyangiaceae

Page 10 
Table S6. The fungal indicator OTUs.

\begin{tabular}{|c|c|c|c|c|c|c|c|c|c|c|}
\hline Otu & month & env & Indval & $\mathrm{p}$ & freq & phylum & class & order & family & genus \\
\hline Otu337 & 5 & nest & 1 & 0.002 & 6 & Zygomycota & Mucoromycotina_I.S & s Mucorales & Umbelopsidaceae & Umbelopsis \\
\hline Otu41 & 5 & nest & 0.833333333 & 0.015 & 5 & Ascomycota & Dothideomycetes & Dothideomycetes_ & I.sMyxotrichaceae & Oidiodendron \\
\hline Otu105 & 5 & nest & 0.833333333 & 0.023 & 5 & Ascomycota & Eurotiomycetes & Chaetothyriales & Herpotrichiellaceae & Exophiala \\
\hline Otu596 & 5 & nest & 0.833333333 & 0.019 & 5 & Ascomycota & Dothideomycetes & Dothideomycetes_ & I.sMyxotrichaceae & Oidiodendron \\
\hline Otu360 & 5 & nest & 0.828719723 & 0.044 & 8 & Ascomycota & Dothideomycetes & Dothideomycetes_ & I.sMyxotrichaceae & Oidiodendron \\
\hline Otu179 & 5 & nest & 0.821759259 & 0.017 & 6 & Ascomycota & Sordariomycetes & Coniochaetales & Coniochaetaceae & - \\
\hline Otu6 & 5 & nest & 0.805976431 & 0.05 & 6 & Ascomycota & - & - & - & - \\
\hline Otu9 & 5 & nest & 0.783169533 & 0.042 & 7 & Ascomycota & Dothideomycetes & Pleosporales & Venturiaceae & - \\
\hline Otu560 & 5 & nest & 0.6666666667 & 0.038 & 4 & Ascomycota & - & - & - & - \\
\hline Otu455 & 5 & nest & 0.6666666667 & 0.05 & 4 & Ascomycota & - & - & - & - \\
\hline Otu400 & 5 & ref soils & 0.833333333 & 0.029 & 5 & Zygomycota & Mucoromycotina_I.S & s Mortierellales & Mortierellaceae & Mortierella \\
\hline Otu112 & 5 & ref soils & 0.824242424 & 0.039 & 6 & Ascomycota & - & - & - & - \\
\hline Otu305 & 5 & ref soils & 0.81871345 & 0.018 & 6 & Ascomycota & Leotiomycetes & Helotiales & Hyaloscyphaceae & Calycina \\
\hline Otu1083 & 5 & ref soils & 0.7777777778 & 0.018 & 6 & Ascomycota & Leotiomycetes & Helotiales & - & - \\
\hline Otu360 & 6 & nest & 0.980904523 & 0.01 & 11 & Ascomycota & Dothideomycetes & Dothideomycetes_ & I.sMyxotrichaceae & Oidiodendron \\
\hline Otu3 & 6 & nest & 0.977127173 & 0.016 & 11 & Ascomycota & Dothideomycetes & Dothideomycetes_ & I.sMyxotrichaceae & Oidiodendron \\
\hline Otu337 & 6 & nest & 0.954545455 & 0.005 & 10 & Zygomycota & Mucoromycotina_I.S & sMucorales & Umbelops & sidaceae Umbelopsis \\
\hline Otu560 & 6 & nest & 0.945454545 & 0.006 & 8 & Ascomycota & - & - & 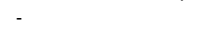 & - \\
\hline Otu76 & 6 & nest & 0.901960784 & 0.033 & 8 & Ascomycota & Pezizomycotina_I.s. & Pezizomycotina_I.s & Sezizomycotina_I.s & Xenochalara \\
\hline Otu20 & 6 & nest & 0.870503597 & 0.044 & 12 & Ascomycota & Dothideomycetes & Dothideales & Dothioraceae & - \\
\hline Otu41 & 6 & nest & 0.833333333 & 0.022 & 5 & Ascomycota & Dothideomycetes & Dothideomycetes_ & I.sMyxotrichaceae & Oidiodendron \\
\hline Otu25 & 6 & nest & 0.833333333 & 0.011 & 5 & Ascomycota & Leotiomycetes & Helotiales & - & - \\
\hline Otu1631 & 6 & nest & 0.833333333 & 0.021 & 5 & Ascomycota & Dothideomycetes & Pleosporales & Venturiaceae & Venturia \\
\hline Otu105 & 6 & nest & 0.833333333 & 0.012 & 5 & Ascomycota & Eurotiomycetes & Chaetothyriales & Herpotrichiellaceae & Exophiala \\
\hline Otu2 & 6 & nest & 0.832702657 & 0.027 & 7 & Ascomycota & Dothideomycetes & Pleosporales & Venturiaceae & - \\
\hline Otu6 & 6 & nest & 0.831882797 & 0.02 & 7 & Ascomycota & $-\quad \quad-$ & $-\quad \quad-$ & & \\
\hline Otu103 & 6 & nest & 0.826446281 & 0.016 & 6 & Ascomycota & Dothideomycetes & Dothideomycetes_ & I.sDothideomycetes_I & I.sScleroconidioma \\
\hline Otu165 & 6 & nest & 0.820707071 & 0.017 & 6 & - & - & - & - & - \\
\hline Otu38 & 6 & nest & 0.81970405 & 0.016 & 7 & Ascomycota & Leotiomycetes & Helotiales & Hyaloscyphaceae & Hyaloscypha \\
\hline Otu12 & 6 & nest & 0.778267254 & 0.05 & 9 & Ascomycota & - & - & - & - \\
\hline Otu697 & 6 & nest & 0.745614035 & 0.033 & 6 & Ascomycota & Eurotiomycetes & Eurotiales & Trichocomaceae & Penicillium \\
\hline Otu258 & 6 & nest & 0.6666666667 & 0.048 & 4 & Ascomycota & - & - & - & - \\
\hline Otu112 & 6 & ref soils & 0.993630573 & 0.004 & 7 & Ascomycota & - & - & - & - \\
\hline Otu89 & 6 & ref soils & 0.884615385 & 0.027 & 12 & Ascomycota & - & - & - & - \\
\hline Otu124 & 6 & ref soils & 0.86875 & 0.04 & 9 & Ascomycota & - & - & - & - \\
\hline Otu199 & 6 & ref soils & 0.861538462 & 0.008 & 10 & Ascomycota & Sordariomycetes & Hypocreales & Clavicipitaceae & Pochonia \\
\hline Otu1083 & 6 & ref soils & 0.833333333 & 0.011 & 5 & Ascomycota & Leotiomycetes & Helotiales & - & - \\
\hline Otu187 & 6 & ref soils & 0.833333333 & 0.019 & 5 & - & - & - & - & - \\
\hline Otu606 & 6 & ref soils & 0.833333333 & 0.02 & 5 & Zygomycota & Mucoromycotina_I.S & s.Mortierellales & Mortierellaceae & Mortierella \\
\hline Otu305 & 6 & ref soils & 0.827338129 & 0.021 & 6 & Ascomycota & Leotiomycetes & Helotiales & Hyaloscyphaceae & Calycina \\
\hline Otu1036 & 6 & ref soils & 0.824275362 & 0.025 & 6 & Ascomycota & Eurotiomycetes & - & - & - \\
\hline Otu564 & 6 & ref soils & 0.807291667 & 0.041 & 6 & Ascomycota & Sordariomycetes & Hypocreales & - & - \\
\hline Otu179 & 8 & nest & 1 & 0.003 & 6 & Ascomycota & Sordariomycetes & Coniochaetales & Coniochaetaceae & - \\
\hline Otu455 & 8 & nest & 1 & 0.004 & 6 & Ascomycota & - & - & - & - \\
\hline Otu41 & 8 & nest & 0.993243243 & 0.007 & 7 & Ascomycota & Dothideomycetes & Dothideomycetes_ & I.sMyxotrichaceae & Oidiodendron \\
\hline Otu321 & 8 & nest & 0.972222222 & 0.008 & 7 & Ascomycota & Eurotiomycetes & Eurotiales & Trichocomaceae & Penicillium \\
\hline Otu20 & 8 & nest & 0.969814241 & 0.045 & 11 & Ascomycota & Dothideomycetes & Dothideales & Dothioraceae & - \\
\hline Otu43 & 8 & nest & 0.852941176 & 0.022 & 11 & Ascomycota & Leotiomycetes & Rhytismatales & Rhytismataceae & Lophodermium \\
\hline Otu105 & 8 & nest & 0.833333333 & 0.016 & 5 & Ascomycota & Eurotiomycetes & Chaetothyriales & Herpotrichiellaceae & Exophiala \\
\hline Otu103 & 8 & nest & 0.833333333 & 0.012 & 5 & Ascomycota & Dothideomycetes & Dothideomycetes_ & I.sDothideomycetes_I & I.sScleroconidioma \\
\hline Otu379 & 8 & nest & 0.833333333 & 0.013 & 5 & Basidiomycota & Exobasidiomycetes & Exobasidiales - & Exobasidiaceae & Exobasidium \\
\hline Otu586 & 8 & nest & 0.833333333 & 0.012 & 5 & Ascomycota & - & - & - & - \\
\hline Otu718 & 8 & nest & 0.833333333 & 0.014 & 5 & Ascomycota & - & - & - & - \\
\hline Otu731 & 8 & nest & 0.833333333 & 0.012 & 5 & Ascomycota & Eurotiomycetes & Chaetothyriales & Herpotrichiellaceae & Exophiala \\
\hline Otu21 & 8 & nest & 0.831056466 & 0.031 & 6 & Ascomycota & - & - & - & - \\
\hline Otu360 & 8 & nest & 0.827228327 & 0.015 & 6 & Ascomycota & Dothideomycetes & Dothideomycetes_ & I.sMyxotrichaceae & Oidiodendron \\
\hline Otu102 & 8 & nest & 0.810810811 & 0.049 & 7 & Ascomycota & Eurotiomycetes & Eurotiales & Trichocomaceae & Penicillium \\
\hline Otu278 & 8 & nest & 0.6666666667 & 0.05 & 4 & Ascomycota & - & - & - & - \\
\hline Otu400 & 8 & ref soils & 1 & 0.002 & 6 & Zygomycota & Mucoromycotina_I.s & s Mortierellales & Mortierellaceae & Mortierella \\
\hline Otu112 & 8 & ref soils & 0.989130435 & 0.005 & 7 & Ascomycota & - & - & - & - \\
\hline Otu124 & 8 & ref soils & 0.970178926 & 0.034 & 10 & Ascomycota & - & - & - & - \\
\hline Otu199 & 8 & ref soils & 0.950413223 & 0.015 & 9 & Ascomycota & Sordariomycetes & Hypocreales & Clavicipitaceae & Pochonia \\
\hline Otu19 & 8 & ref soils & 0.886792453 & 0.04 & 11 & - & - & - & - & - \\
\hline Otu89 & 8 & ref soils & 0.827794562 & 0.023 & 11 & Ascomycota & - & - & - & - \\
\hline Otu52 & 8 & ref soils & 0.826771654 & 0.025 & 6 & Ascomycota & Leotiomycetes & Helotiales & Hyaloscyphaceae & Lachnum \\
\hline Otu138 & 8 & ref soils & 0.826558266 & 0.025 & 6 & Ascomycota & Leotiomycetes & Helotiales & Vibrisseaceae & Phialocephala \\
\hline Otu79 & 8 & ref soils & 0.785714286 & 0.024 & 10 & - & - & - & - & - \\
\hline Otu80 & 8 & ref soils & 0.75 & 0.04 & 9 & - & - & - & - & - \\
\hline
\end{tabular}

